(r) ( البحث رقم

التتاذرات المرضية للمبانى السكنية وعلاقتها بالتفاعلات الصحية التحسسية الأسباب والحلول من خلال تصميم العمارة الداخلية

Syndromes in Residential Buildings and its Relation to Allergic Symptoms, Diagnosis and Treatment by Designing Interior Architecture

د/ مني أحمد قاسم محمد حسن محمد حسين

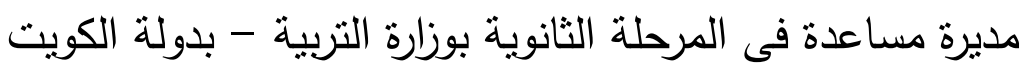


يعاني العالم المتحضر الآن من انتشار أمراض التحسس(")، فخلال الأربعين عام الماضية ظهر على الإنسان حالات متكررة من التحسس("*) تجاه مكونات البيئة المحيطة به، ويعاني الآن واحد من كل ثلاثة في العالم المتقدم من أحد أثنكال التحسس(10)، وفي الوقت الذي يجتهد فيه الطب والأطباء للوصول إلى تشخيص تلك الحالات وأسبابها ثم إكتشاف الدواء المناسب لها، كان المصممون والعاملون في صناعة البناء يعملون جاهدين لخلق بيئة داخلية جميلة ومعدره سواء داخل المباني، ونتج عن ذلك تصنيع العديد من أجهزة التحكم البيئي ومواد البناء ومواد النهو والتشطيب المصنعة لتكون أعلى جودة وأطول عمرا وسهله التشكيل والتركيب، وفي نفس الوقت أقل نكلفه. وقد نجحت صناعة البناء في ذلك بالفعل، وكلما أزداد ذلك النجاح وزاد تحكم الإنسان في بيئته الداخلية أرتفعت معدلات التحس. لا شك أن خلال السنوات العشر الماضية توجه العديد من رواد صناعة البناء لدراسة الآثار البيئيه لمواد البناء ومواد النهو والتشطيب، وتركزت معظم تلك الأبحاث في دراسـة علاقة تلك لك روت المواد بجودة الهواء داخل المباني، وتم تطوير العديد من المواد الصديقة للبيئة بصورة عامه، التي لا تؤثر بالسلب على البيئة المحيطة أثناء صناعتها أو بعد تركيبها، والعديد من تلك المواد آثاره التحسية قليلة، ولازال رواد العمارة والعمارة الداخلية الخضراء يجتهدون لتحقيق اهدافهم البيئية. ولكن الأمر لازال في حاجة لتخصيص الدراسات والأبحاث لإنتخاب مواد النهو والتتطيب التي لا

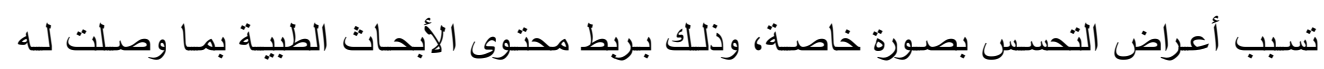

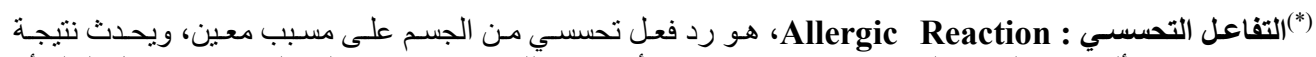

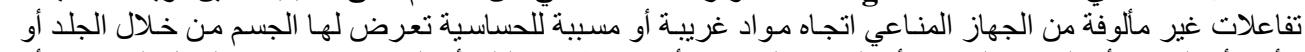

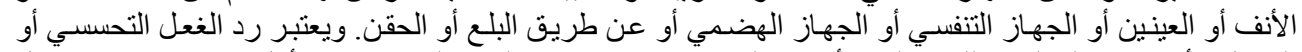

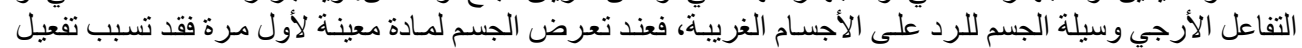

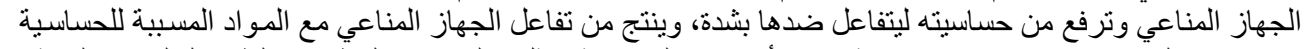

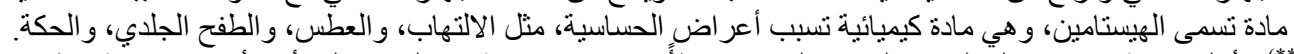

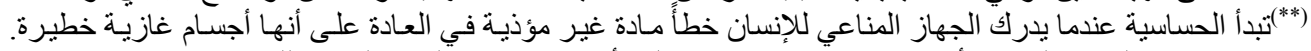

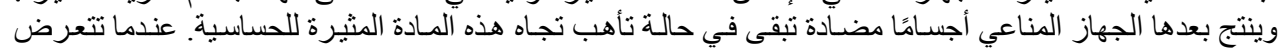

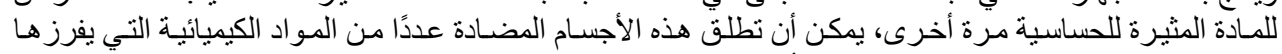
(الجهاز المناعي، مثل الهيستامين الذي بسبب أعر اض الحساسية. 
صناعة البناء من دراسات بيئية، فتضيئ لنا الأبحاث الطبية الطريق إلى تشخيص جيد للمشكلة وتتاذراتها وتحديد تتاذرات المبنى المريض ثم الاستفادة من الدراسات البيئية الهندسية لطرح الحلول التصميمية للعـلاج. لذلك نرجو ان يكون هذا البحث خطوة إيجابيـة تجاه عمل إطار تصميمى لصناعة بناء صحية خالية من مثيرات التحسس.

مشكلة الدر اسة:

تتتـاول هذه الدراسـة العلاقـة بين متغيـرين، حالـة المبـاني السكنية والتفـاعلات الصـحية التحسسية لقاطنيها، وقد يتبادر للذهن أن هذين المتغيرين يصسعب قياسـهما، فما المقصـود بحاله المباني، هل حالتها التصميمية أم الإنشائية أم عملية النهو والتشطيب. إلى جانب ما هو المقصـود بالتفاعلات الصحية التحسية لقاطنيها، هل حدتها أم معدل تكرارها بالنسبة للفرد أم معدل ظهورها على أفراد الأسره الواحده أم ماذا؟

لاشكك أن حدود المتغيرين غير واضحة، وكذلك العلاقه السببية للمشكلة الناتجه عنهما، فالانفصـال بين الأطبـاء والمصممين يتسبب في خلق منطقة ضبابية لا تتضـح بها الروئبا وتكون النتيجة مباني سكنية مريضـه تحمل بين أروقتها كل مقومات وأسباب المرض وتكون حالات التحسس والأزمات الصحية لقاطنيها هي فقط أعراض ذلك المرض. لقد حان الوقت ليترك المصمم مقعده ويشـارك الأطباء معانـاتهم مـع المرضسى أو العكس حتى نتمكن مـن توضيح الصورة ومعالجة المشكلة ونوقف المصمح عن إفساد عمل الطبيب دون فصد. التساؤ لات :

بدأت التسـاؤلات نطرح نفسها، في البدايـة أثنارات أصسابع الاتهام إلى ارتباط ذلك بتلوث الهواء outdoor air pollution وعوادم السيارات. ولكن الغريب أن بلدان لا تعاني من التلوث

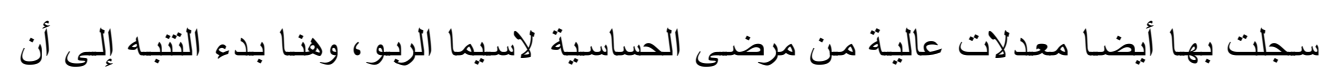
مسببات التحسس ليست ناتجة بصورة أساسية لما يحدث خارج الأبواب Outdoor، بل لما يحدث 
داخلها indoor. وهنالك العديد من الأدله العلمية الآخذه بالإزدياد على وجود علاقة قوية بين تصميم المبانى الذي يقضي بها الإنسان أكثر من •9\% من وقته وصحة ساكنيها.(or) أن المشكله تكمن في البيئه الداخلية المحيطة بالإنسان، وأستمر الطب والأطباء في تطوير اساليب وأدوية العلاج، ولكن لم يتوقف المصممون عن تطوير أسباب الداء! تطرح هذه الدراسة سؤالين: • مـا هـي العلاقـة بـين التــاذرات المرضـية للمبـاني السـكنية وبـين التفـاعلات الصـحية التحسسية لقاطنبها؟ ما هي الحلول التصميمية للعمارة الداخلية المقترحة ؟

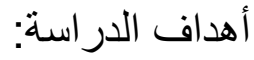

ظهرت ابحاث عديدة نوضح لنا مخاطر المبنى امريض وسوف يتم تعريف المبانى المريضة والعناصر المسبية لتلوث البيئة الداخلية للمباني وظواهر ذلك، فللعلم والبحث العلمي عدة أهداف وأهم هذه الأهداف، استكثـاف المشكلة، ثم وصفها، ثم شرحها وتفسيرها لتمام فههها، تم محاولة التتبؤ أو التوقع بمسارها وما تؤول إليه أو ما قد يحدث إذا سارت الأمور سيرا معينا، وفى النهاية محاولة ضبطها والتأثنير عليها ووضع الحلول التصميمية لها، وذلك

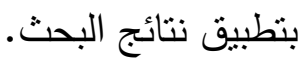

تهـدف الورقـة البحثيــة تحقيـق الموضــوعية وفـرض الحقـائق الخاصــة بالمجـالين الطبـي والتصميمى بصورة تزيل عنها كل شك مقبول (مع ملاحظة أن الحقائق العلمية ليست ثابتة، بل هي حقائق بلغت درجة عالية من الصدق قابل للتغيير بتقدم البحث العلمي)، وذلك بتحقيق الآتي: ( ) الإعنمادا على الدراسات الطبية المتخصصة وتتخيص المشكله، وذلك على النحو التالى: التعرف على أمراض التحسس ووصفها وعرض خصائصها وأعراضها ، حتى بسهل تتاولها من غير المتخصصين، لاسيما المصممين.

$\left.{ }^{52}\right)$ D'Alessio, Vittoria; 2011- The Allergy-Free Home, Ibied., 
تقسير مسببات ومهيجات حالات التحس،، وتحديد أماكن تواجدها داخل المبنى.

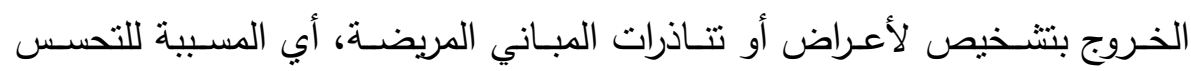
معتمدا في ذلك على بعض الدراسات السابقة مع اضافة بعض النقاط المستتنجة من الدراسات الطبية والتي من المتوقع أن تزيد من المشكلات الصحية بالمباني.

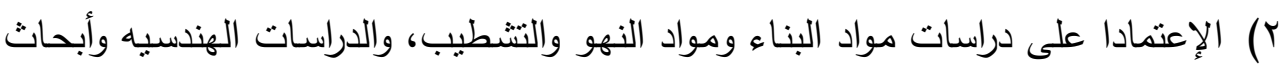
العمارة الخضراء نم إستنتاج الحلول، وذللك علنالنحو التالى: تحديد المواد البديلة والأجهزة التي يمكن استخدامها في تصميم وتتفيذ المباني لتحقيق أفضل الحالات الصحية لمرضى التحس... وضـع مقترح لمستويات التعامل مـع تلك المباني لضبط تلك المشكلات وحلها إمـا بصورة جذرية أو موضعية حسب حاجة المبنى.

المنهج الاستقرائي والذي يعرف أحيانا بطريقة "من الأسفل نحو الأعلى". وكذا الدراسات الوصفية التحليلية. فالتحليل الاستقرائي. يبدأ بالملاحظات والقياسات المحددة للمتغيرات غير المحدده ثم نستكثف الاتساق والانتظام بينهم لنصيغ الفروض المبدئية التي يمكننا استكثافها ثم ننتهي بتطوير بعض الاستتناجات العامة التي تؤطر المشكله.

وسوف نحاول اجراء عملية من التنظيم الصـيح لسلسلة من البيانات النوعية والأفكار والدراسات الطبية العديدة لأعراض وأسباب التحسس، لنتمكن من وصف العلاقات القائمة بين الظواهر الصحية وربطها بواقع مكونات ومواد البناء ومواد النهو والتشطيب والأثاث المستخدم بـالحيزات الداخليـة المحيطـة بـالمريض ثـم ترتيـب تلـك الوفـائع ترتيبـا معينـا، بحيـث يمكن ملاحظتها بطريقة موضـوعية، نسـاعدنا على رصد المتكرر منهـا وبالتـالي يتم الربط بين المقدمات والنتائج الصحية، وبين أسبابها داخل البيئة المبنية (الحيزات الداخلية). وسوف نعرض نتيجة هذه الدراسة بصورة ملخصة ليسهل استخدامها والاستفادة منها، مقارنـه بحقيقة الدراسات التي مكنت الباحثة من الوصول لهذا الإيجاز . 
المبنى السكنى المريض هو حيز تم تصميمهُ بطريقة لم يُراعى فيها جودة البيئة الداخلية

لقاطنية، ولم يراعى فى تصميمه جودة البناء، والتشطيب. ومن الملاحظ مستخدمى بعض المساكن يعانون من بعض الأعراض المرضية التى تلازمهم أثتاء وجودهم بالداخل نتيجة تكون بيئات غير صحية وسرعان مـا تختفى أو تقل عند المغادرة وهذا مـا يطلق عليه"متلازمـة البناء المريض" والتى تحدث فى حولى • ب\% من الأبنية الحديثة التى أصبحت من الأعراض المعروفة عالميا نتيجة إعتلال الهواء الداخلى.(r) أثزر أمر اض المبنى على الإنسان: - ملى

أن أسلوب تشييد المباني الحديثة واستخدامها يعكس الكثير من الأضرار على البيئة ويهدد بتدهور صحة الإنسان، وتقدر الكميات التي تستغلها هذه المباني من الموارد الطبيعية بسدس

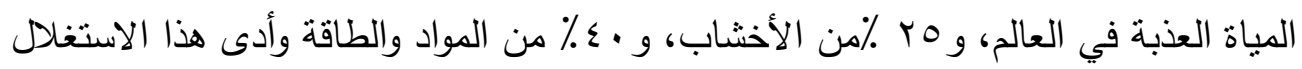
إلى آثار جانبية بيئية مثل : التصحر ، تلوث الهواء والماء واستتفاذ طبقة الأوزون في الغلاف الجوي، واحتمال التعرض لزيادة دفء هذا الكون، بالإضافة إلى أن ما يقرب من • ب٪ من المباني الجديدة تعاني من"متلازمة البناء المريض مما يعرض ساكنيها والذين يقضون حوالي ـ ٪ من حياتهم داخلها إلى استتشاق هواء غير صحي، ففي المئة عام الماضية ارتفعت نسبة ثاني أكسيد الكربون في الهواء بنسبة VY ٪ جاء ربعها من حرق الوقود الحفري لتزويد

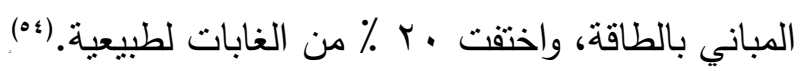

(") أسامة أحمد عبدة ومحمد سمير الصاوى، دراسة مبلئية عن الإنبعاثات الصادرة من مواد البناء والتشطيبات ، كلية

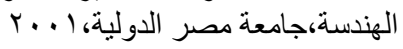

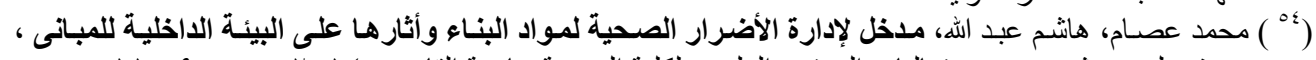

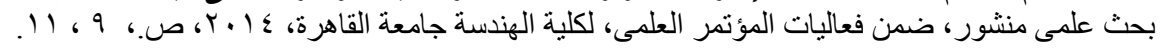


نتيجة لأنشطة الإنسان اليوميـة تتسبب المبانى المريضـة في تلوث البيئة، فالغـازات

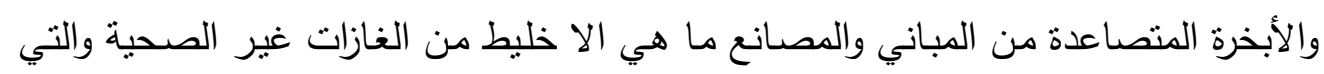

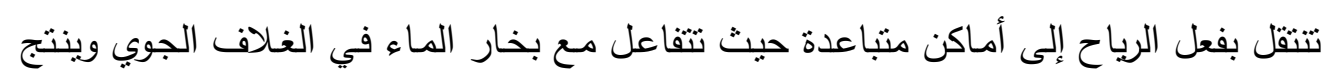
عنها الأمطار الحمضية والتي تسبب غابات وأنثجار ميتة وبحيرات لاحياة فيها.

أما المركبات العضوية المنظايرة "Volatile Organic Compounds " والتي نستخدم بكثرة

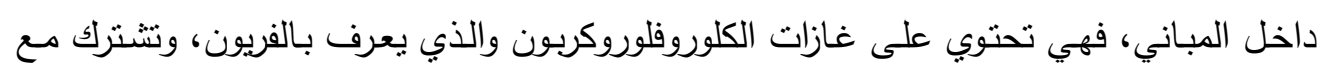

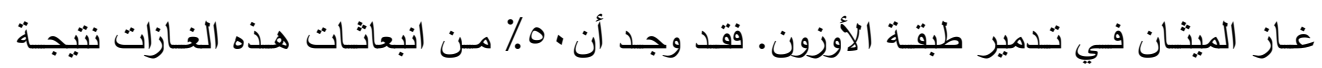

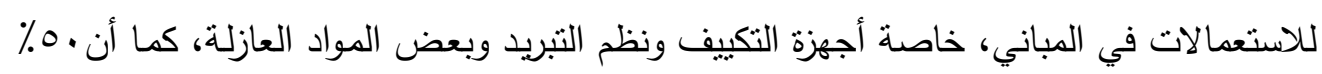

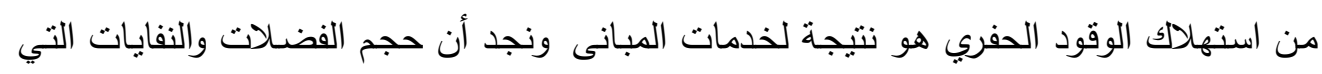

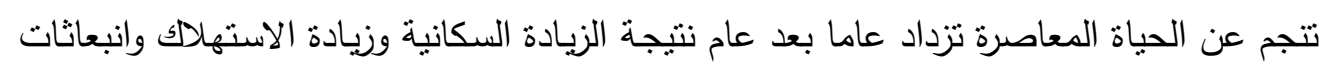
الملوثات والنفايات الناتجة من المباني.

يؤدي دفن النفايات في النربة إلى التحلل العضوي وانطلاق الغازات السامة (الميثان)، كما

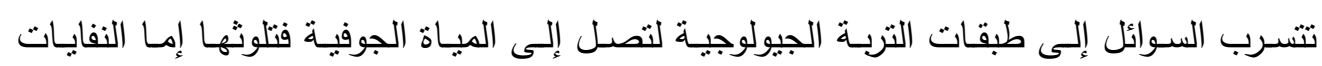

البلاستيكية الناتجة من مخلفات المباني ينتج عنها غاز كلوريد الهيدروجين السام عند حرقهها. التأثير السلبي لمصادر التلوث على الإنسان:

تتنكل كثرة مصادر التلوث داخل الحيزات الداخلية خطراً كبيراً على صحة الإنسان، فيمكن

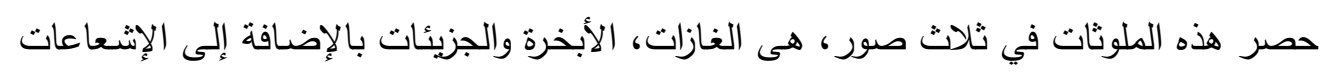

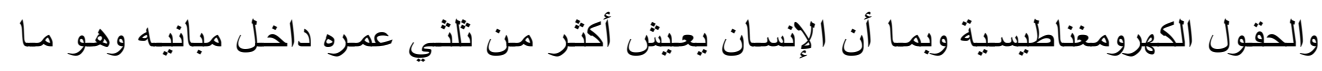

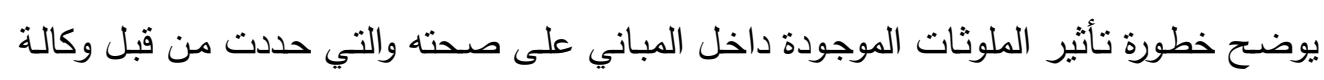

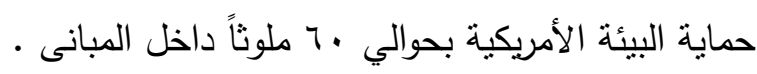


ومن أمثلة هذه الملوثات استخدام مادة البولي يوريثين السامة في دهانات الأخثاب، كما أن

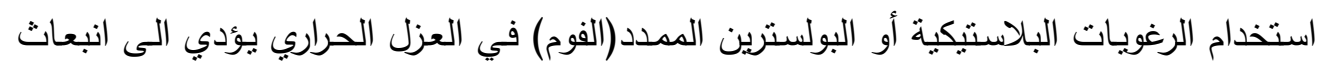

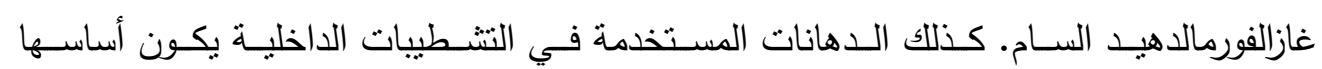

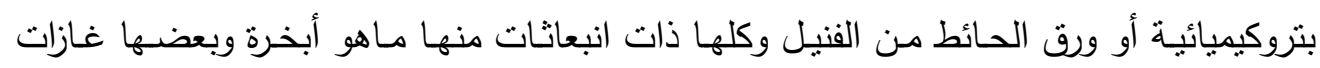
ومركبات عضوية متطايرة،كذلك استخدام الأصباغ والمواد اللاصقة في صناعة الألواح الخشبية

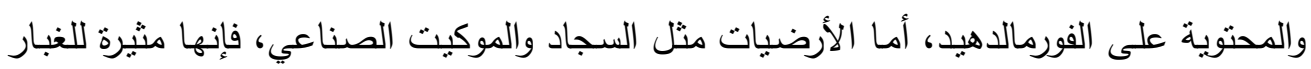

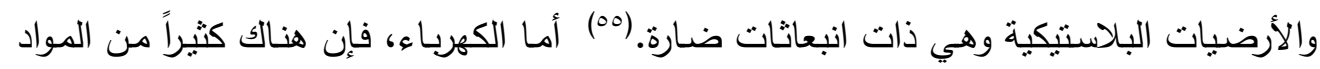

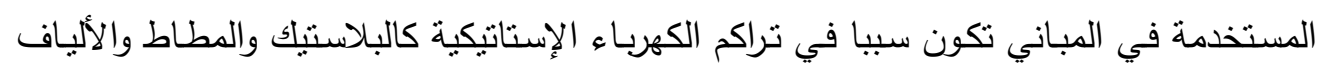
الصناعية والسجاد المصنع من الفوم وتزيد هذه الإنتاتيكية في الغرف سيئة التهوية. من هنا نجد ان ظاهرة أعراض المبنى المريض والتي تحدث في •ـ ٪ من المباني، قد أصبحت معروفة عالميا وباستخدام وسائل التهوية الصناعية، فإن ذلك غالبا ما يؤدي الى انتثار المركبات غير الصحية، كما ان المباني المحكمة الغلق تحبس المركبات العضوية المنطايرة والتي تؤدي الى زيادة احتمالات التعرض لمرض السرطان أو الخلل في الجهاز المناعي. النفايات ومواد البناء كمصدر للضرر داخل المباني: إن المباني تتضمن الكثير من المنتجات التي تحتوي على العديد من الكيماويات الخطرة

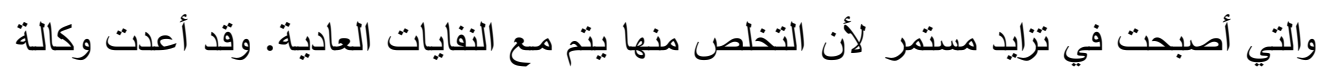

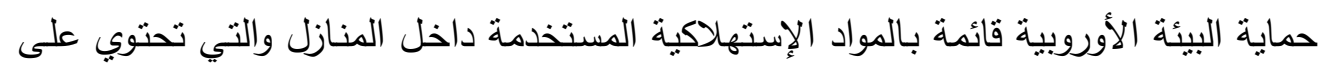
مواد خطرة، (07) والجدول رقم (1) يوضح هذه القائمة

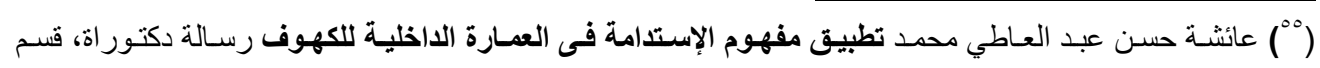

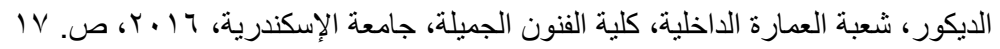

(7) محمد عصام، هاشم عبد الله، مدخل لإدارة الأضرار الصحية لمواد البناء وأثارها على البيئة الداخلية للمبانى، مرجع 


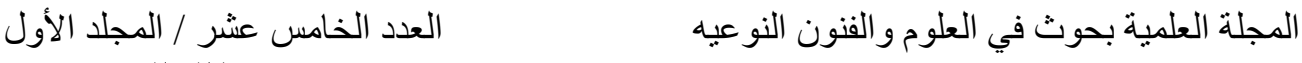

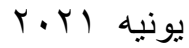

\begin{tabular}{|c|c|}
\hline النفايات الخطرة الناتجة منها & 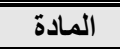 \\
\hline معادن ثقيلة، أصباغ،مذيبات،بقايا عضوية. & الا هانات \\
\hline مركبات الكلور العضوية،ومذيبات عضوية & البلاستيك \\
\hline أصباغ،معادن ثقيلة،مركبات الكلور العضوية & الأثثاث \\
\hline معادن ثقيلة ،أصباغ ،أملاح طلاء أكلة،زيوت فينولات & 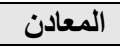 \\
\hline معادن ثقيلة & الجلود \\
\hline مركبات الكلور العضوية ،مركبات الفسفور العضوية & المبيدات \\
\hline معادث ثقيلة ومن أهمها الرصاص والكادميوم & البطاريات \\
\hline
\end{tabular}

(جلول r) (الملوثات المنبعثة من مواد البناء وأنواع الأثاث المختلفة بالبيئة الداخلية

\begin{tabular}{|c|c|}
\hline الملوثات المنبعثة & نوع المادة \\
\hline 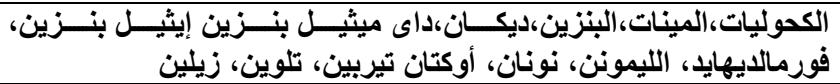 & المواد الاصقة Adhesives \\
\hline 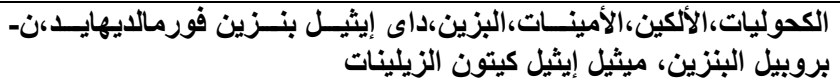 & $\begin{array}{l}\text { مركبات المسناج (المعجون) } \\
\text { Caulking Compounds }\end{array}$ \\
\hline بنزينيلبروبيل بنزين أستيرين انديكانين، دوديكان،فينيل سيكلو هسكان،ميثيل إيثيل & $\begin{array}{c}\text { مواد تصنيع اللسجاد } \\
\text { Carpeting }\end{array}$ \\
\hline الفورمالديهايد & Ceiling tiles بلاط الأسطح \\
\hline 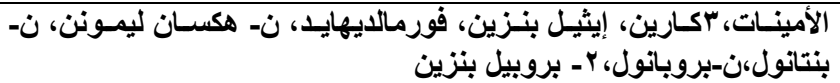 & أغطية الأسطح (بلاطات، رقائق خشبية) \\
\hline 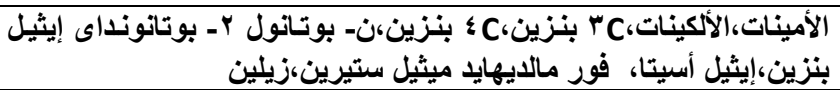 & $\begin{array}{c}\text { أغطية الأرضيات والحوائط } \\
\text { Floor and wall coverings }\end{array}$ \\
\hline بنزينيلإيسو إيثانول، إيسو إيثيل أسيتات، أيسو بروبيـل بنزين، ليمونين، & 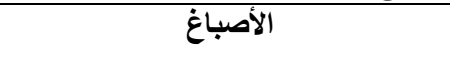 \\
\hline الأمينات،بنزين،ديكان Decan،دوديكان،فورمالديهايد ن- هبتان & $\begin{array}{l}\text { طلاء الصباغة والورنيشات } \\
\text { Stains and varnishe }\end{array}$ \\
\hline الفورمالديهايد & مواد التجيد Upholstery \\
\hline الأمينات،ن- ديكان،فورمالديهايد، او كو ـ - تراى ميثيل بنزين، الزيلين & $\begin{array}{c}\text { ورق الحائط المغطى بالفينيل } \\
\text { Vinyl-coated wallpaper }\end{array}$ \\
\hline
\end{tabular}

( ) محمد عصام، هاثشم عبد الله، مدخل لإدارة الأضرار الصحية لمواد البناء وأثثار ها على البيئة الداخلية للمبانى، مرجع سابق. (1) فرحسات محروس، ملوثـات البيئة الداخليـة للمبـانى وأعراض المبنـانى المريضـة، مؤسسـة الكويت للتقدم العلمى،

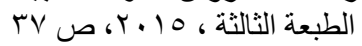


• المواقد والدفايات التى تعمل بالكيروسين أو الفحم والأخشاب وتعتبر من الملوثنات الغازيـة

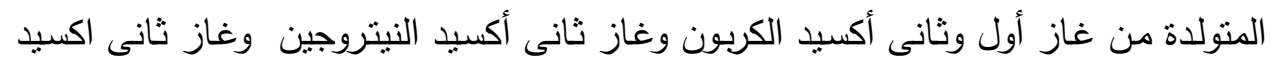

$$
\text { الكبريت والجسيمات الاقيقة .. وغيرها. }
$$

• ألياف الأسبتوس من مواد البناء والنهو والتتطيب والمواد العازلة ومواد مقاومة الحريق والأثاث

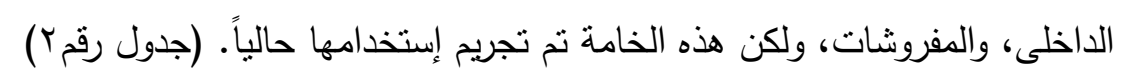

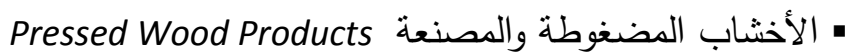

• المبيدات الحشرية المتتوعة والمنظفات والمواد الكيميائية ومواد الصيانة المنتوعة. • أنظمة التهوية والتبريد والتنخين غير النظيفة والملوثة بالكائنات الدقيقة.

• أجزة حفظ الرطوبة Humidification Devices • مواد حفظ وتلميع الأخشاب والأرضيات.

• الأصباغ والمواد الاصقة المستخدمة فى العمارة الداخلية.

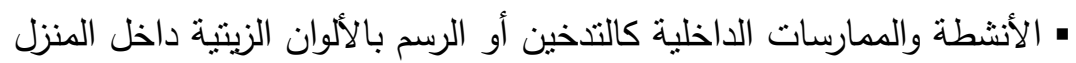

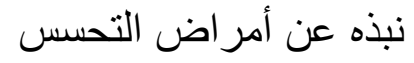

التحسس يعد من الأمراض ذات الإستعداد الوراثي التي يمكن أن تظهر في أية مرحلة من

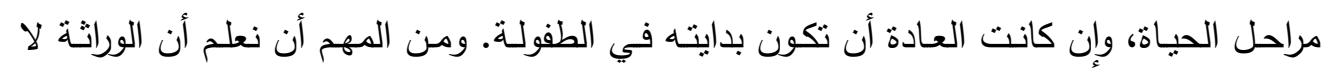

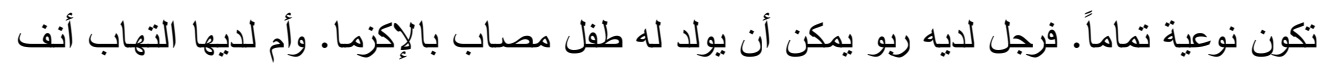

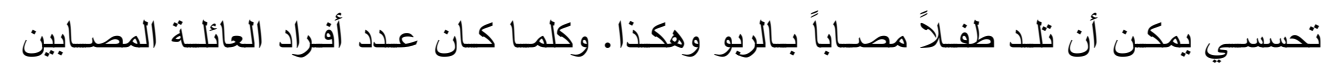

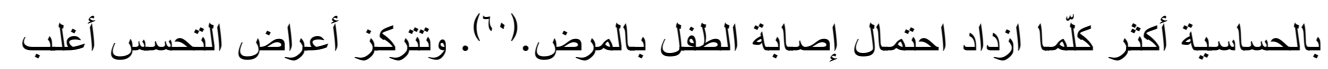
الأحيان في الجهاز الهضمي والجهاز التتفسي (حاسية الصدر، الربو والتهاب الجيوب الأنفية)

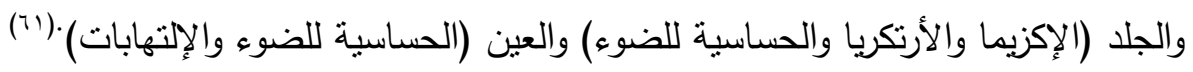

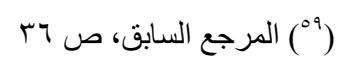

$\left({ }^{60}\right)$ Dr. Basel Khatib's Pediatric Web Site. http://khatib.com/index.htm, 2008

$\left({ }^{61}\right)$ D'Alessio, Vittoria;2001-The Allergy-Free Home,A Practical Guide to Creating a Healthy 
عندما يتعرض شخص ما إلى أحد المواد المسبية للحساسية لأول مرة ينتج جهاز المناعة لديه كميات غير عادية من البروتينات الدفاعية تسمى الأجسام المضادة،(وهي تدعى الكروينات المناعية اميونوجلويولين ( IgE)(") . ودور أجسام ( IgE) هو تمييز المواد المثيرة للحساسية، هذه الأجسام المضاده تلتصق بخلايا مناعية خاصة تسمى الخلايا السمينة. هذا النوع من الخلايا موجود في جميع أنحاء الجسم كالرئتين والأنف والجلد. خلال التعرض الثاني تميز تلك الأجسام العوامل المثيرة للحساسية وتعمل على تتبيـه الخلايـا السميه("*) لكي تطلق مـا يدعى (الوسـائط المناعية) ومن أنثهر هذه الوسائط الهيستامين histamine.

إن إفراز هذه الوسائط يؤدي إلى أعراض التحس حسب مكان وجود الخلايا السمية التي تم تحريضها. فإن كانت في الرئنتن حصلت أعراض الربو (كالأزيز الصدري) وإن كانت في الجلد

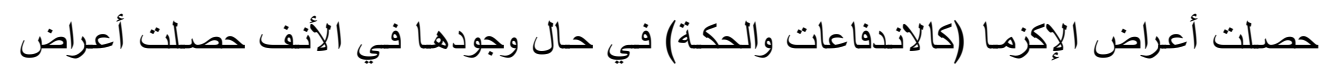
التهاب الأنف التحسسي (كسيلان الأنف المـائي والحكـة الأنفيـة). وفي الحسالات الثـديدة مـن التحس يحصل ما نسميه (التأق) كذلك الذي يحصل مثنلاً في حالات التحسس الثديد للبنسلين حيث يؤدي الأمر إلى أعراض مهددة للحياة كنقص الضـط وضيق التنفس والصدمة والحكة

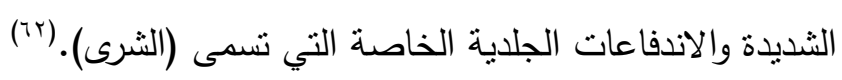
ولنقف على الصورة الحقيقية لمرض التحسس ومدى تأثثره وتهديده لحياة الإنسان، نأخذ حساسيه الربو كمثال، فالربو (") هو المرض المزمن الأكثر شيوعا بين الاطفال، وهو أما أن يكون داخلي المنشأ وهو الناتج عن الإلتهابات الفيروسية التنفسية، أو خارجي المنشأ (وهو

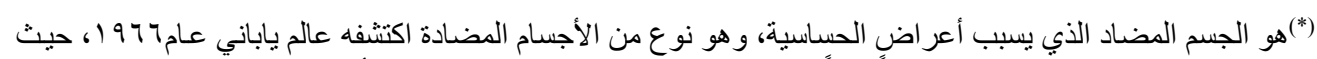

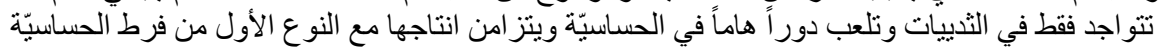

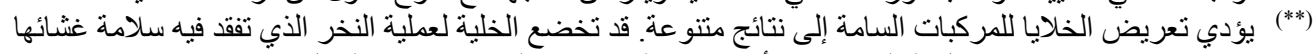

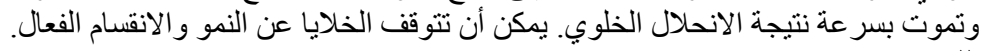

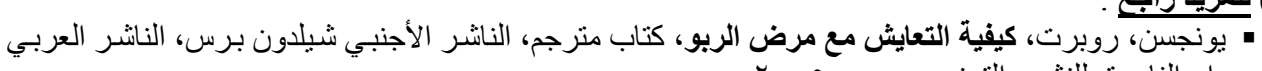

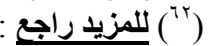

- Dr. Basel Khatib's Pediatric Web Site. http://khatib.com/index.htm, 2008

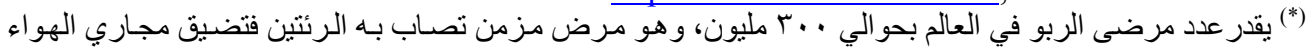

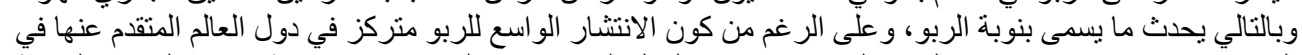

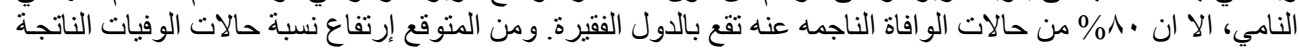

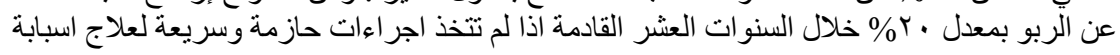


الأكثر شـيوعا) وهـو النـاتج عـن تحسس الثـخص بصـورة غيـر عاديـة تجـاه بعض المـواد الموجودة بالبيئه المحيطة المثيرة للحساسية. ويؤثز الاستعداد الوراثي تأثنرا شديدا على استعداد الثخص للمواد المثيرة للتحس، ويمكن أن يكون الثخص مصابا بالنوعين معا.(rآ) لقد خلصت العديد من الدراسـات إلى أن العوامل البيئية مثل التلوث والتدخين والحيوانـات الأليفة داخل المنزل أو ما أسمنه الدراسات عمليات التغير المستمرة في اسلوب الحياه المعاصر ومكان ممارسـة هذه الحياه التي يحيى بها الإنسـان معظم وقته سـاهم في ازدياد حالات وحدة ازمات الربو (ء؟) لذلك، وعلى الرغم من كون الربو مرض لا يرجى شفاءه (وكذلك باقي أمراض التحسس)، الا أن اتخـاذ بعض الاحتياطـات العلاجيـة والتصـميمية والمعيشـية بالبيئة المحيطـة بالمريض للحد من مهيجات التحسس قد تؤدي إلى السيطرة عليه ومن ثم يتمكن المريض من العيش بصورة شبه طبيعية

العو امل المسببه للتحسس Allergy Triggers:

وهي مواد اما طبيعية أو مصنعة تحيط بنا في الحياة اليومية وليس من المفترض أن يعاملها الجسم على كونها مواد غريبـة يجب أن يدافع عن نفسه ضدها، ولكن مرضي التحسس عندما يتعرضون لها ينتج جهاز المناعة لديهم كميات غير عادية مما سبق ذكره من البروتينات الدفاعية المسماه الأجسام المضادة والهستامين مما يسبب لديهن أعراض تحسسية. وأغلب المباني تحتوي على مواد قد تثير ردود أفعال غير عادية في أجسام فاطنيها، هذه المواد تتقسم إلى نوعين:

\section{$\left({ }^{63}\right)$ World Health Organization, 2008, Regional office for Europe.}

(') Al Frayh AR, Shakoor Z, Gad El Rab MO, Hasnain SM. Parental smoking and the risk of childhood asthma, available at http://www.ncbi.nlm.nih.gov/pubmed/ 
(Allergens) عو امل مسببة للحساسية)

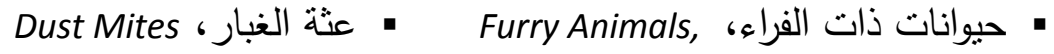

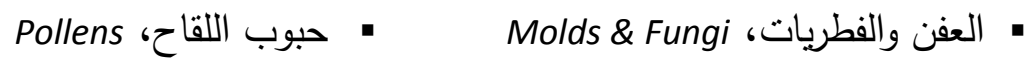

$$
\begin{aligned}
& \text { Cockroaches ، الصراصير ت }
\end{aligned}
$$

Smoke, Cigarette ، الدخان والسجائر •

Scented Products, VOCs المواد المهيجة، كالمنظفات والمعطرات،

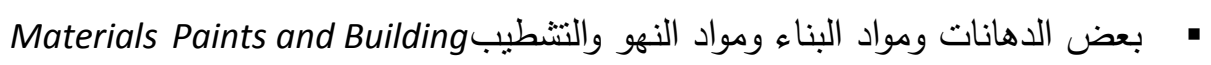

Chemicals المواد الكميائية، كالمبيدات

Air Pollution تلوث الهواء،

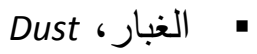

Changes in weather and temperature،التغير بدرجات الحرارة،

Foods \& Drugs،بعض الأدوبة والأطعمة ت ل

يلاحظ أن الغالبية العظمى للعوامل المسببة للتحسس تحبط بالإنسان في الحيز الداخلى أي

داخل المبني لا خارجه، وقد اثبتت الدراسات أن مستويات التلوث بالداخل قد يزيد من الضعف

وحتى خمسـة أضعاف عن الخـارج.(70). وأن تلوث الهواء بالداخل تم تسـيله كأحد أهم خمسـة

أسباب للمخاطر الصحية البيئية EPA Indoor Environments Division. كما تم تسجيل العديد

من حالات التحسن في نوبات الربو أو الانتكاس بمجرد انتقال المريض لمسكن آخر .

ما هو المبنى المريض

دلـت الإحصـائيات علىى انتشــار أمـراض الحساسـية بالمنـاطق الحضـرية خاصــة بـالبلاد

الصناعية، وهناك العديد من الأدله العلمية الآخذة بالازدياد على وجود علاقة قوية بين تصميم

$\left({ }^{65}\right)$ American Academy of Allergy, Asthma, and Immunology. [Web site], on the World Wide Web: http://www.aaaai.org/aadmc/default.htm 
المبنى وصحة قاطنيه. فماذا حدث في الخمسين سنه الماضية حولت المباني إلى مسبب للأزمات

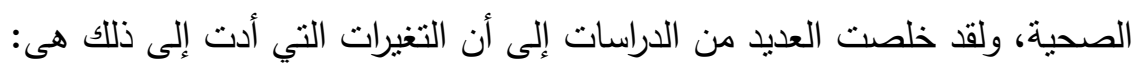

• تصميم المباني المغلق وأسلوب تهويتها، حيث زاد التركيز على التهوية الصناعية مما زاد من تركيز الملوثات في الهواء داخل المباني. • المواد المستخدمة في انثاء المباني ومواد النهو والتشطيب)|المصنعة أو معالجة بمواد كميائية، وتحتوي على مواد كميائية منظايرة غير ثابتة VOCs ، Volatile OrganicCompounds وهي

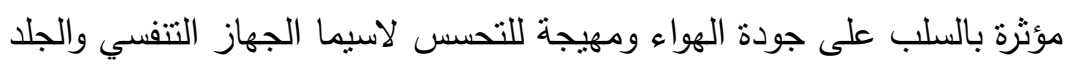

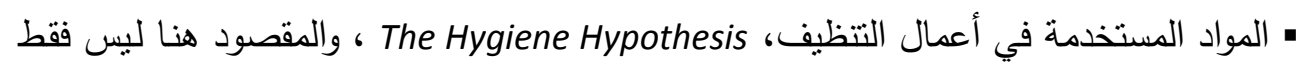

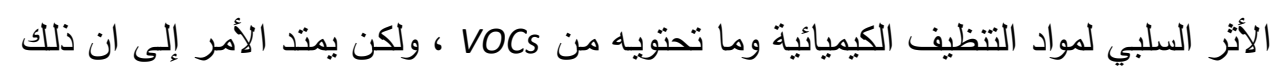

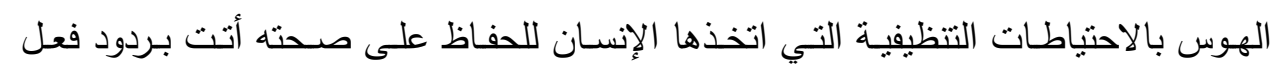

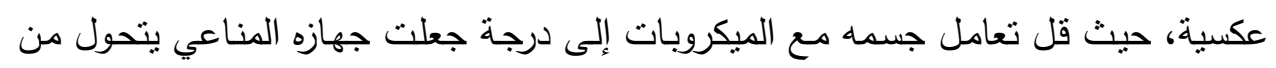

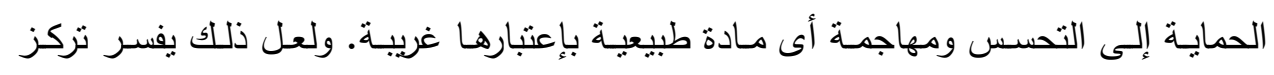
الاصابات بالتحس في سكان المدن والبلاد المنقدمة.

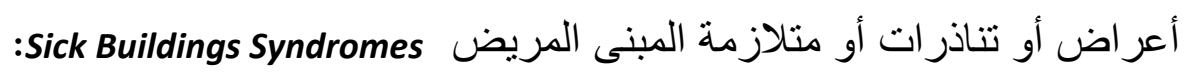
لوحظ أن العديد من الأبحاث عندما تتتاول دراسـة تتاذرات المبنى المريض، كانت تصب

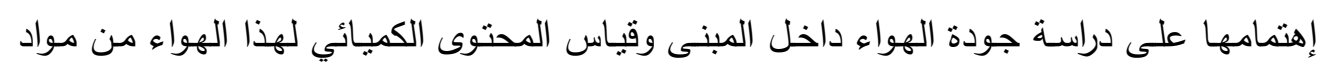

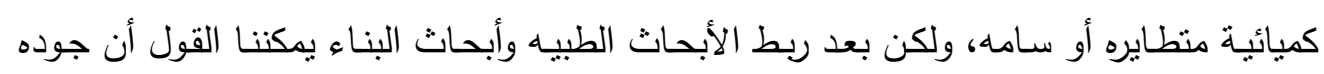

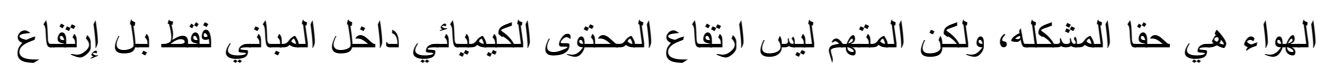
المحتوى الحيوي أيضا، ثم يحكم حلقات المشكله التهويه غير الجيده للمبنى، وذلك كالآتي: • ارتفاع المحتوى الحيوي داخل المبنى Biological Contaminants، اجتمعت الدراسات

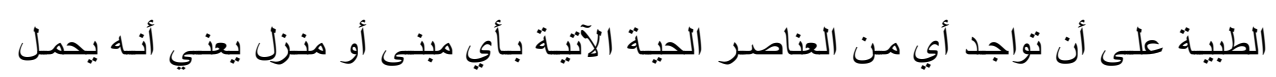

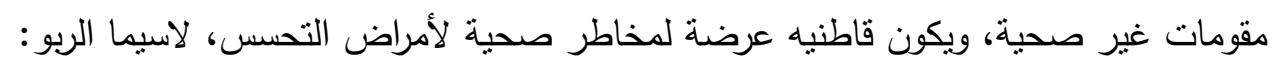


م عثة الغبار، Dust Mites(")، وهي حشرة مجهريه يبلغ طولها r. . . مم، وتتخذى على خلايا الجلد الميت وقشرة الرأس المنساقطة على الفرش والسجاد والموكيت، وتنتمو وتتكاثر خصوصاً

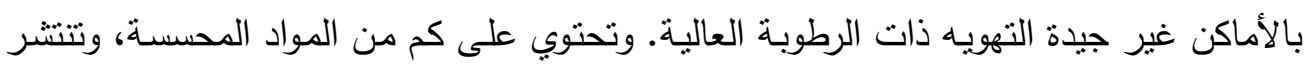

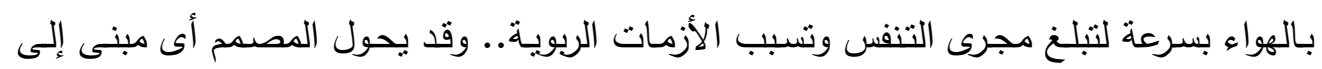

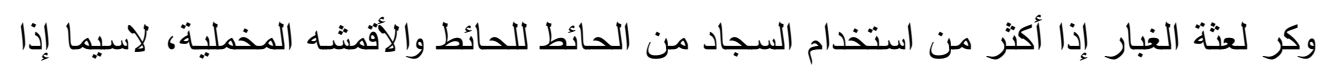

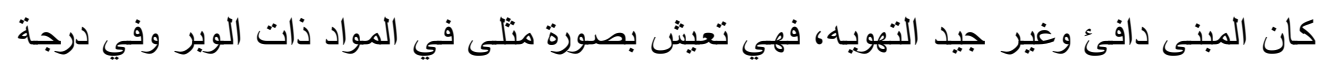

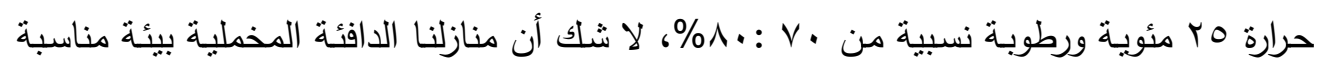

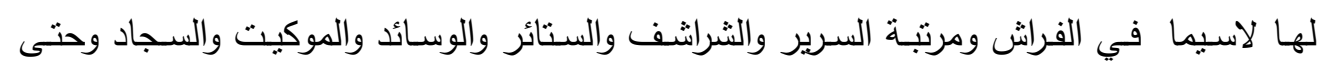

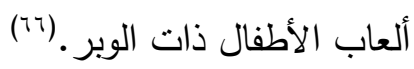
o العفن والفطريات Molds \& Fungi، من أكثر الملوثات العضوية تواجدا في المبنى غير جيد

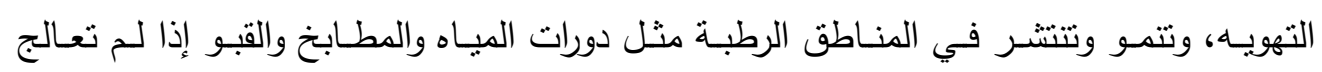

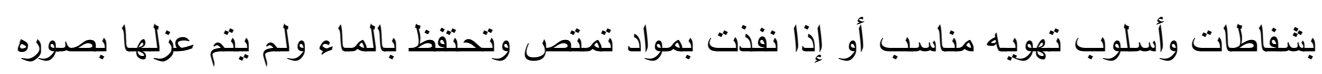

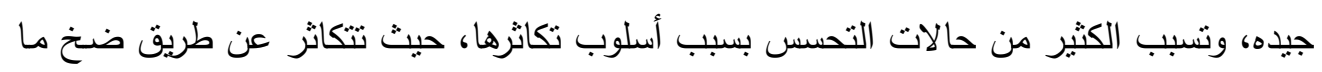

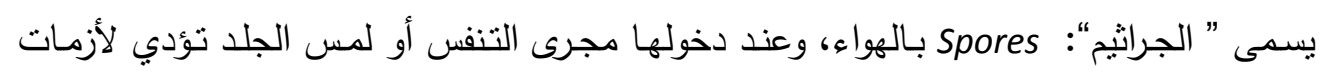
الربو أو الإكزيما.

o حبوب اللقاح، Pollens، وهي من مسببات العديد من أنواع الحساسية. وكلما كبر حجم حبيبه

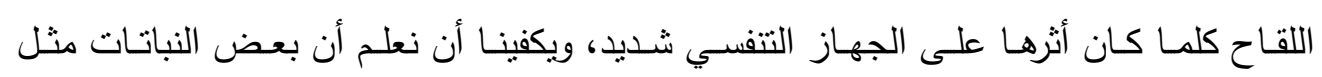
ragweed الحساسية التي قد تتسبب عنها إذا اختار المصمم استخدامها. o الحيوانات ذات الفراء، Furry Animals, Pets \& Pests

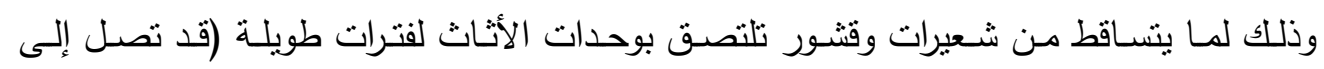

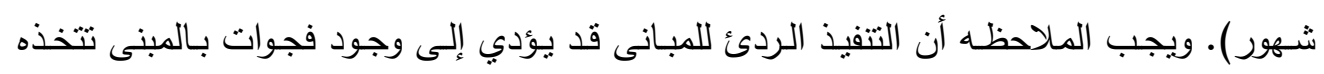

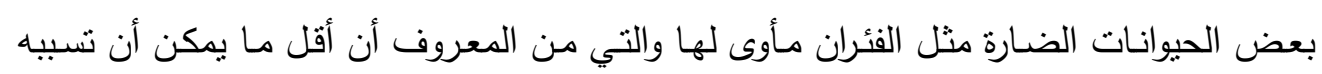
للسكان هو الحساسية، ناهيك عن الأمراض الأخرى منل الطاعون.

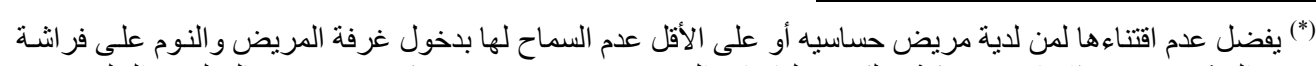

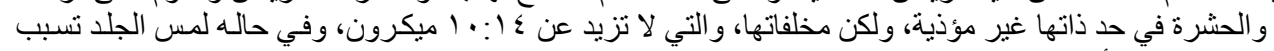

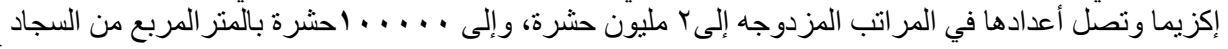

$\left({ }^{66}\right)$ D'Alessio, Vittoria; 2001- The Allergy-Free Home, Ibid., 
O الصراصير، Cockroaches، مخلفات الحشرات المنزلية من مسببات التحسس، وتشطيب وتأثيث المبنى الغير جيد يوفر الثقوق التي تعيث وتتكاثر ويصعب لمكافحتها. • مسببات العدوى Infectious Agents، وذلك بتعرض المريض الذي يعاني من التحسس لعدوى

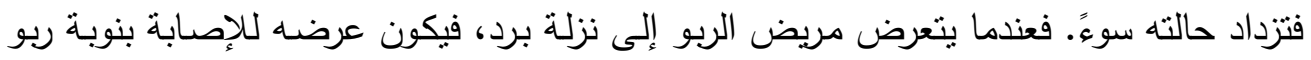

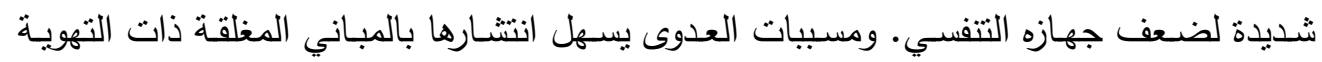

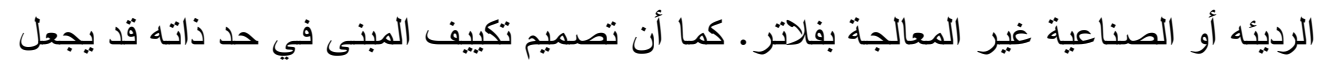
جسم الإنسان مستعد لتلقي العدوى، ومثال لذلك عدم تدرج درجات الحرارة عند مداخل المباني،

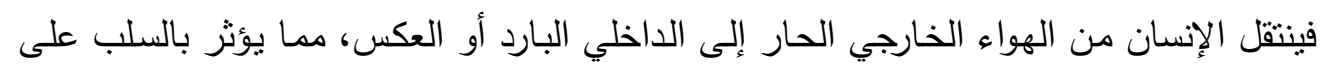
مجاري الهواء بالجهاز التنفسي ويسهل الإصابه بنزلات البرد. • إرتفاع الملوثات الكيميائية Chemical Contaminant يؤدى الاستخدام الواسع للمواد المصنعة في عملية البناء، وفي الاستخدام المنزلي، على زيادة المشكلات الصحية ومثيرات التحسس. فمواد الصواد البناء والدهانات والصبغات والسجاد والمنظفات ودخان السجائر ومستحضرات التجميل ومعطرات لاتهر

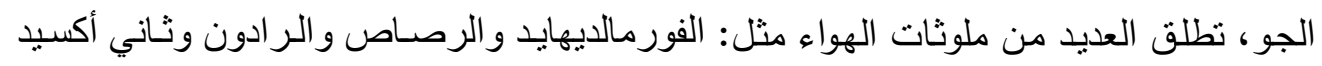
النيتروجين وأول أكسيد الكربـون(*)، بسبب استخدام أجهزة التكييف والتبريد (صناعية التهويه)

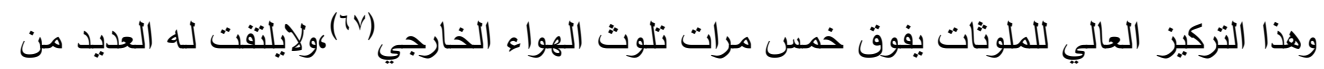
الناس حتى من يستتشقونه.("*) ومن أهم تلك الملوثات:

o المركبات العضسوية المتطايرة volatile organic compounds (VOCs)، هي مواد كلما زاد تركيزها بالهواء داخل المبنى كلما قلت جودته، فهي تتسبب في تحسس القنوات التتفسية والجلد

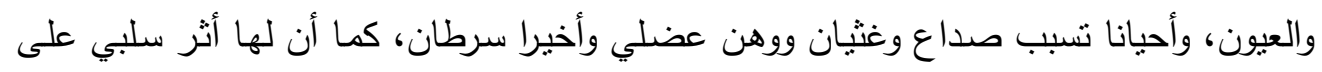

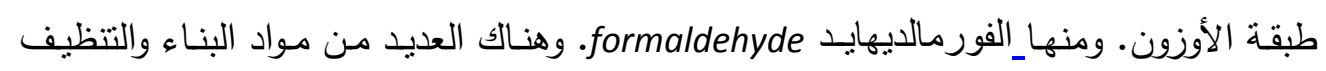

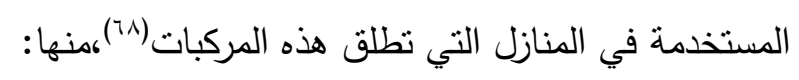

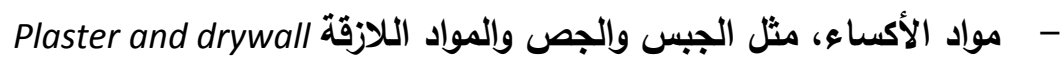

Formaldehyde, Lead, Radon, Nitrogen Dioxide and Carbon Monoxide ${ }^{(*)}$ $\left({ }^{67}\right)$ World Health Organization, 2008, Regional office for Europe, Ibid.,

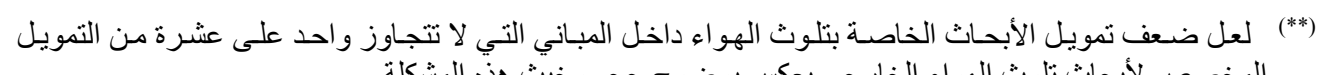
$\left({ }^{68}\right.$ http://www.healthybuilding.net/pdf/Healthy Building_Material Resources.pdf 
- الأخشـاب المصنعة والمعالجها("*)": منتجات الخشب المصنعة والمعالجة (ألواح حبييية، خشب

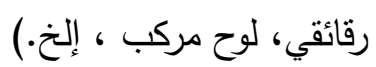

oil-or alkyd-based paint الدهانات الزيتية والورنيش : دهان ور اتنج وورنيش زيني أو ألكيد) resin and varnish

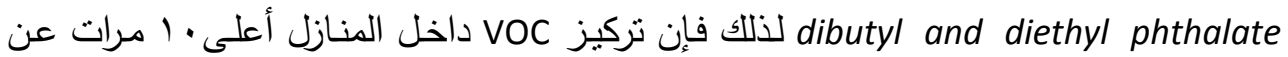
خارجها، وترتفع هذه النسبة إلى . . . مرة اذا كانت الدهانات حديثة ورطبه. وما تتبعث خارج

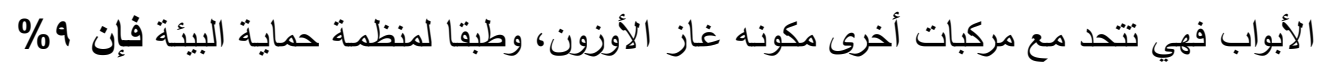

$$
\text { من تلوث الهواء الذي ينتج عنه أوزون يأني من الدهانات. }
$$

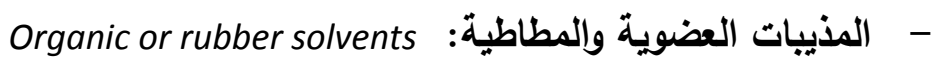

- العديد من أنواع ورق الحائط Wallpaper -

- أرضيات القنيل Vinyl floor coverings -

Synthetic carpeting, padding and adhesives السجاد الصناعي" -

- مغض المنظفات ومعطرات الجو Some cleaning compounds -

o اللائن أو بوليمارات الفنيل، أي المواد البلاستيكية، والأكثر أستخداما في مواد النهو والتشطيب

هى مادة الفنيل/PVC polyvinyl chloride or viny)، هي الأسوء على الإطلاق، وتدخل في تصنيع

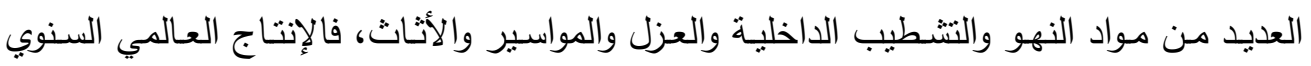

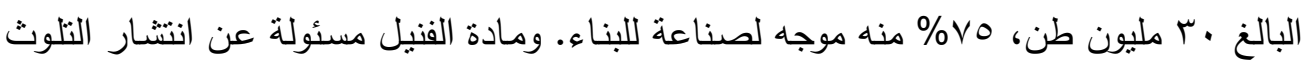

البيئي بالسموم، وبالذات لمـادتين الديوكسين والفنالات dioxin and phthalates ، ويوجد

مشتقات أخرى منهـا تنـتخدم الغالبيـة العظمى في أعمـال التمديدات ولهـا نفس الأثر البيئي

م البوليبرومينـات PBT based material treatments، وهـي مــواد مبلمـرة أسـاس تكوينهـا

polybrominated ، ولقد أنتبت الدراسات نراكمها في أنسجة جسم الإنسان بصورة منذرة ، وهي

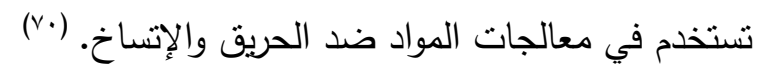

${ }^{(* \star)}$ Manufactured and treated wood products (particle board, plywood, composite board, etc.

$\left({ }^{69}\right)$ Tohn, Ellen, 2006, Building Guidance for Healthy Homes, ARC, Asthma Regional Council of New England, available at, www.asthmaregionalcouncil.org

$\left({ }^{70}\right)$ Tohn, Ellen, 2006, Building Guidance for Healthy Homes, Ibid., 
مeavy metal additives and المعـادن الثقيــة : إضـافات ومكونـات المعسادن الثقيلـة components، وهي معادن لها تأثير سمي أكثر منه تحسسي، مثل الزئبق المستخدم بوحدات الإضـاءة ، والرصاص المستخدم في العزل والتمديدات، والكادميوم المستخدم في الدهانات وفي وني بعض منتجات PVC. م غاز الرادون Radon ، وهو غاز سام منواجد بالطبيعة، ويعد ثاني أسباب سرطان الرئة، تواجدة

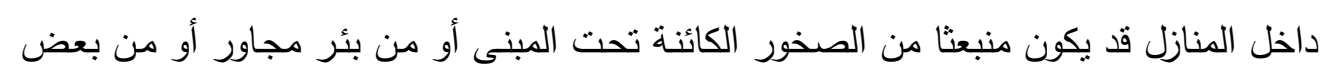

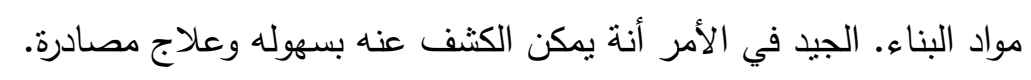

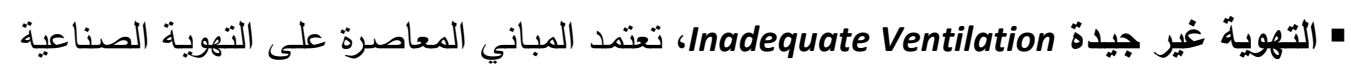

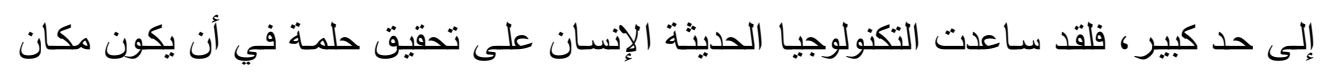

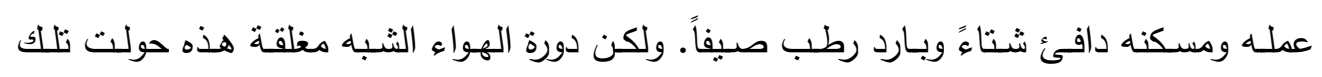
المباني إلى معمل تدوير للمحسسات والميكروبات وجعلتها بؤرة للمخاطر الصحية. ومما قد يزيد

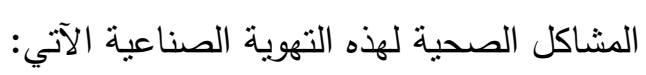

0 0 o 0 تكون مناطق ضغط سالب للهواء فيسحب الملوثات والمعلقات من خارج إلى داخل المنزل ثم عدم

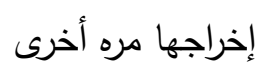

0 م ضعف أو تعطل مراوح شفط المطابخ والحمامات، مما قد يزيد الرطوبة ويتسبب في نمو الفطر

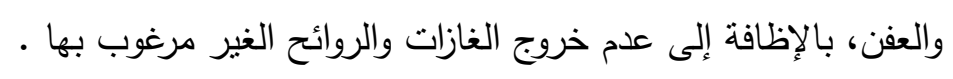

0

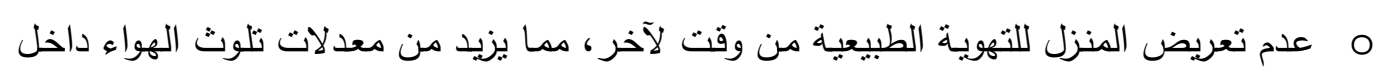

أن الشروط الصحية التي يجب تحقيقها لعلاج التناذرات المرضية للمباني هي:

$$
\begin{aligned}
& \text { • جاف ونظيف Dry \& Clean } \\
& \text { • جيد التهوية Well Ventilated جية }
\end{aligned}
$$

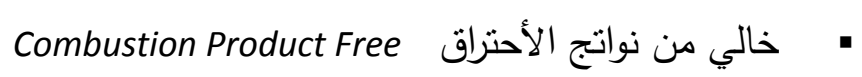

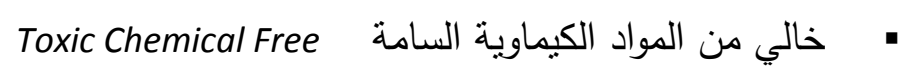




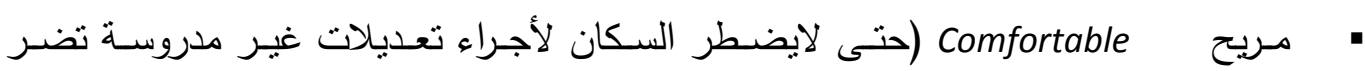
بالشروط الخمسة المذكورة أعلاه)

تم البحث في المواقع الإلكترونيـه لثركات البناء وإنتاج مواد النهو والتشطيب، حتى اعـ نتمكن من حصر الحلول والمواد الصحية التي تساهم بصورة وقائية وعلاجيـة لحل مشكلة مثيرات التحسس في المباني. وإنتهت هذه الدراسة إلى إقتراح نوعين من الحلول: • الأولى حلول جذرية ووقائية، وهي التي يمكن إجرائها لحماية المبنى من حدوث تلك التناذرات، وذلك أثناء مرحلة التصميم الداخلى والتتفيذ وذلك كالآتي: 0 عند أختيار موقع البناء وعمل المخططات المعمارية مرداء 0 مند إختيار نظام التهوية الصناعية وإحتياطات نركيباتها 0 عند إختيار مواد البناء ومواد النهو والتتطيب وإحتياطات تركيباتها O عند التأثيث وفرش المسكن تصميم العمارة الداخلية. - الثانية : حلول موضعية وعلاجية، هي التي يمكن إجراءها لعلاج مشكلات مبنى قائم بالفعل وتم

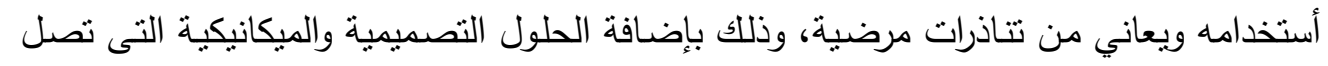
به وبسكانه إلى الراحه الصحية إن شاء الله : 0 0 0 الحلول الوقائية: عمل المخططات التصميمية (*):

• الإهتمام بالنوافذ والأبواب وتوفير التهوية الطبيعية بالمبنى ومناطق جلوس خارجية.

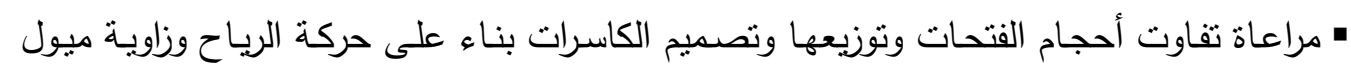
أشعة الثمس.

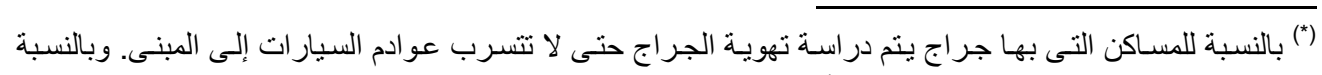

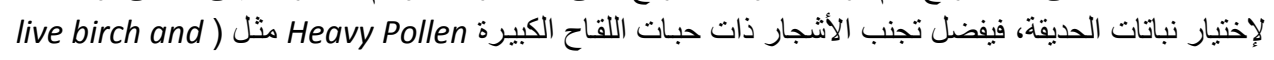
olive ) o olive 
• عدم توجيه المبنى بإتجاة الرياح المتربة، وعند الضرورة يجب معالجة ذلك بأسيجة شجرية. كما يجب وضع الوظائف الرطبة والمنتجة للروائح مثل المطابخ والحمامات وغرف الغسيل في اتجاه معاكس لاتجاه حركة الرياح وتثتتع بأشعة شمس كافية.
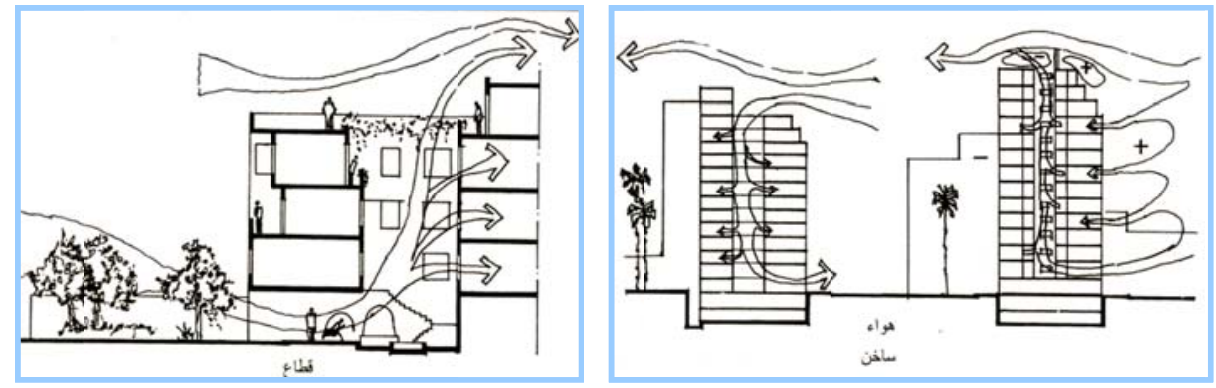

( شكل (') ("التهوية الطبيعية تمثل أهم استراتيجيات المسكن المتوافق بيئيا لتقليل العبء الحرارى
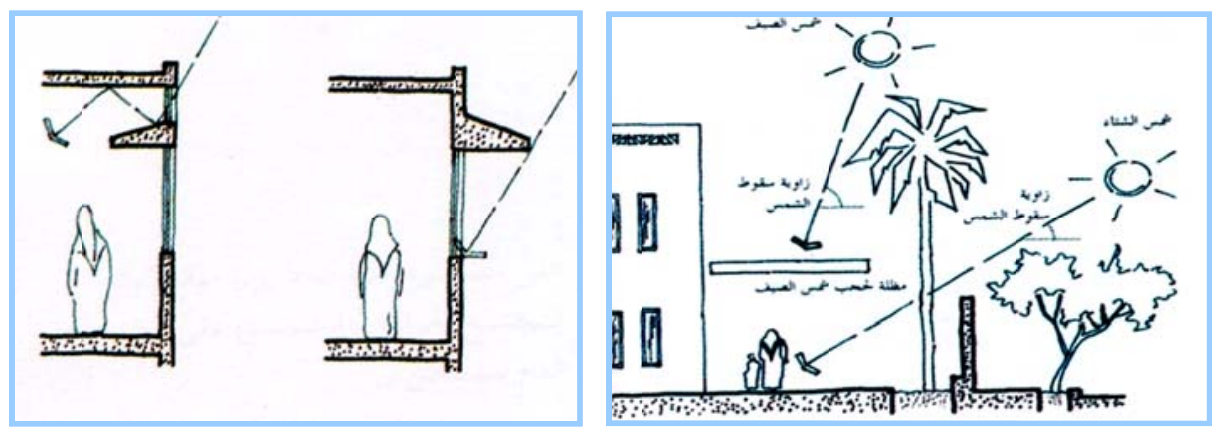

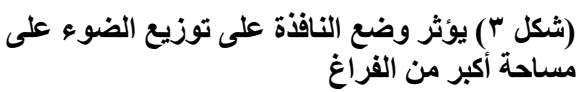

(شكل ץ) الاستفادة من الاشعاع الثمسى بقدر المستطاع

نقل الطبيعة للتصميم الداخلي(Vr): يكون هذا من خلال نقل الصور واللوحات الطبيعية المرسومة واستخدامها في الداخل على الدى الوسائد والستائر أو أقمشة الأرائك، حيث يبدو معظم القماش الداخلي ذو رسوم طبيعية.

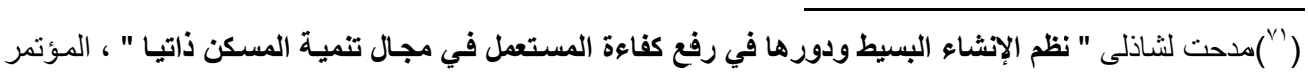

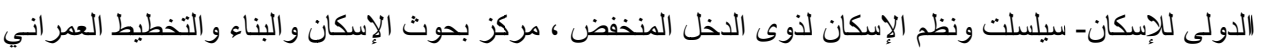

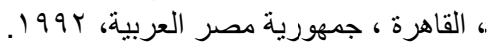

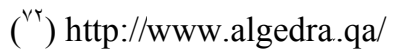




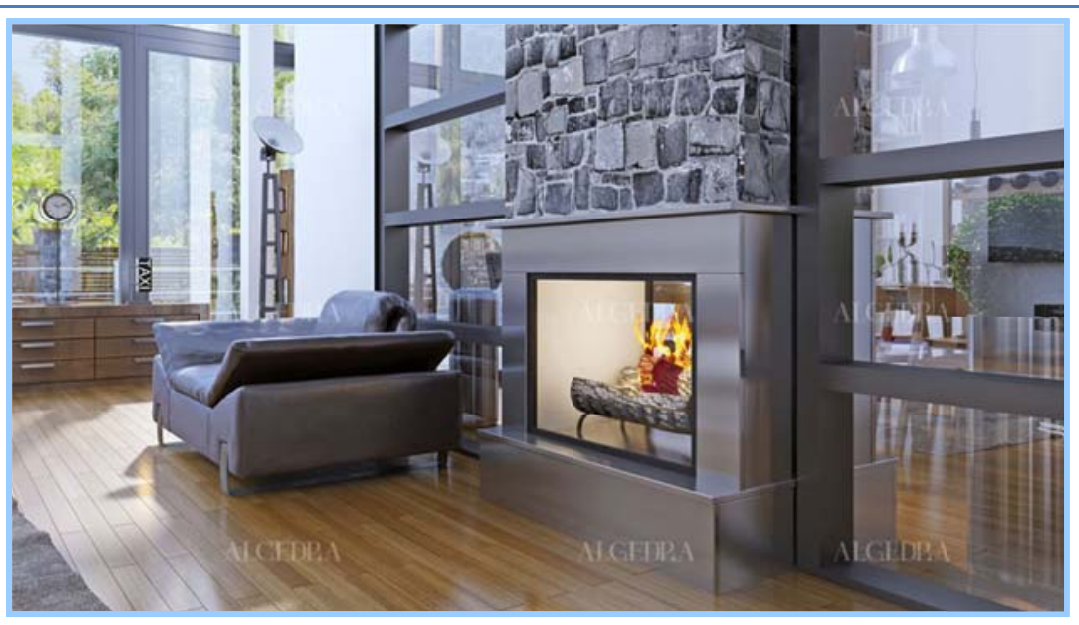

$$
\begin{aligned}
& \text { (شكل ؛) لقطة منظورية من مسكن خاص } \\
& \text { اثنتملت عناصر التصميم الداخلي على مواد طبيعة مثل الخثب أو الحجر في التصميم } \\
& \text { إستخدام نظم تهوية صناعية صحيه : }
\end{aligned}
$$

لا شك أن موضوع نظم التهويه في حاجة إلى العديد من الأبحاث المتخصصة، ولكن لنلقي الضوء على اهمية هذا الجانب اثتاء عملية تصميم وانشاء المبنى، يمكن أن نلخص مـا يجب

$$
\text { مراعاته عند تصميم نظام التكييف والتهوية في الآتي: }
$$

• تركيب وحدة تنقية هواء على نظام التكييف المركزي،|(") أجهزة تتقية الهواء المركزية والمنزلية مع HEPA - أستخدام فلترات بنظام HEPA لينظف الهواء من العوالق مهما كانت دقتها، HEPA Filters and Air Cleaners • ألستخدام وحدة تحكم في الرطوية Dehumidifiers على نظام التكييف المركزي

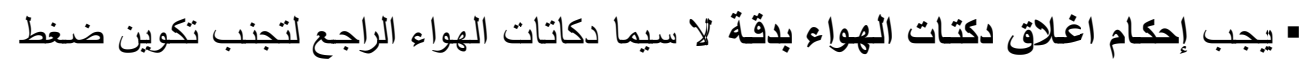
سالب للهواء فيسحب الملوثات والمعلقات من خارج إلى داخل المسكن.

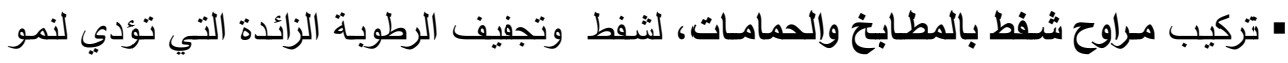

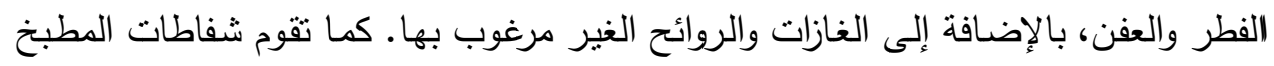
يتقليل مخاطر التعرض لملوثات نواتج الاحتراق ولاسيما غاز أول أكسيد الكربون.

${ }^{(*)}$ Whole House \& Central Air Purifiers with HEPA (High Efficiency Particulate Absolute) 
• تظم التدفئه، يجب دراسـة المداخن بدقه والموازنه بين قوه وحدات التذفئة وحجم الحيز الذي

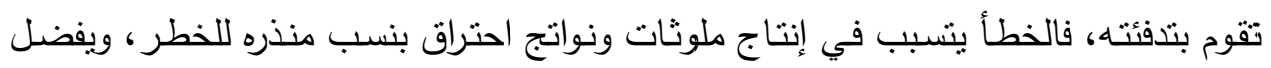

$$
\text { الستخدام أجهزه لرصد ارتفاع معدلات غاز أول أكسيد الكربون }
$$

تصميم دائم ومستمر (VT)

ان الاستمرارية في العمـارة تفخر بـالمزج بـين الثـكل والوظيفـة، فـن المهـم التركيز على لـى

استخدام عناصر التصميم الداخلي التي لا تبدو كبيرة الحجم فقط ولكن مصنوعة بشكل جيد وقليلة التأثير على النظام البيئي. واشتملت عناصر التصميم الداخلي على استخدام مواد طبيعية مثل الخثب أو الحجر، وهما وسيلة لتحقيق الهدف، وهذه المنتجات غالبا ما يكون لها عمرا أطول.

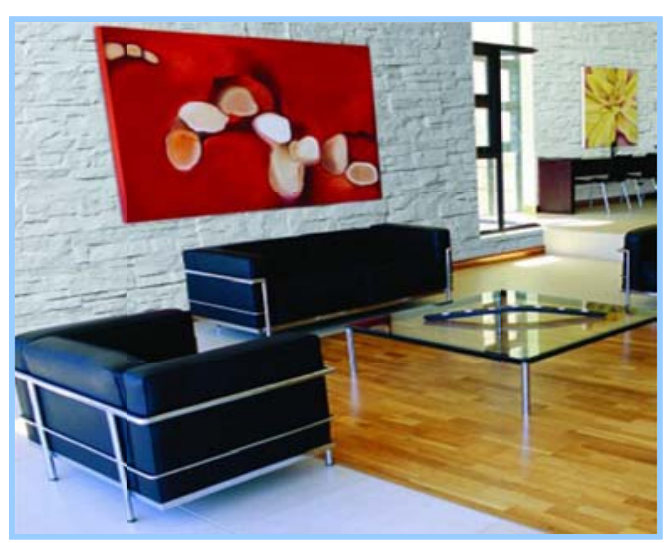

( شكل ؟) استخدام الحجر بعد دهانه باللون الأبيض

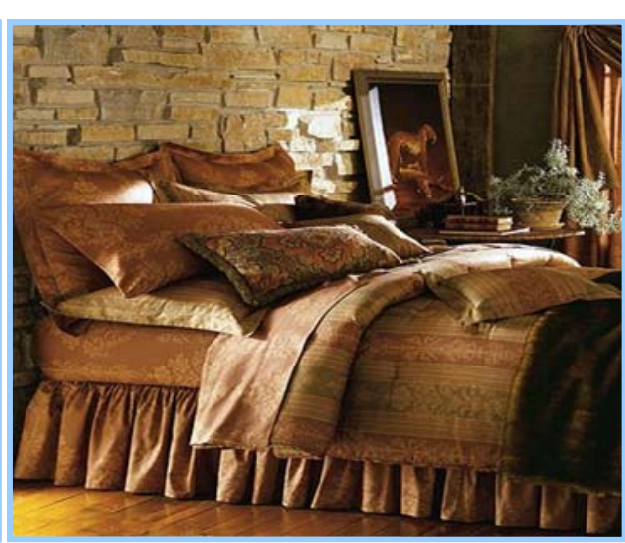

( شكل ه) استخدام الحجر بحالته الطبيعية دون إضافات

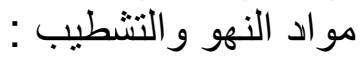

التشطيب هو عملية نهو مفردات العمارة الداخلية متمثلة في الحوائط والأرضيات والأسقف للمبنى حيث تتحدد حسب نوع المواد المنفذة منها والمعالجة الخاصـة بها، وتعتبر التشطيبات السطح الظاهري المنظور في أجزاء المبنى سواء الداخلي منها أو الخارجي •

وأعمال التشطيبات تشتمل على جميع الأعمال التي تجعل جميع حيزات المبنى صـالحة للقيام بوظائفها المصممة من أجلها، وتعتبر مثل الجلد بالنسبة لجسم الإنسان فهي التي تعطي المبنى الثكل والملامح النهائية وتكسبه الثخصية المتميزة.

$\left(^{r w}\right)$ http://www.algedra.qa/ 


\section{Paints الدهانات}

تطورت الدهانات والورنيشـات وذلك بفضل البحث الجـاد والاستثمار الأمثنل واستخدام

التكنولوجيا المتطورة في التصنيع والتطبيق. ويمكننا التمتع بالألوان الجميلة فى مسكننا دون

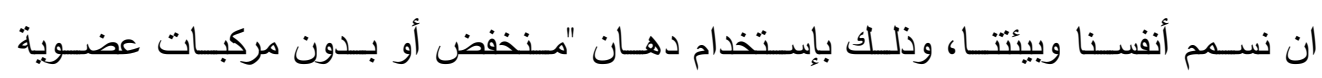
منطايرة" non toxic paints or "low or no VOC" paint. وهي قفزة صناعية هائلة، حيث تستخدم العديد من الشركات نسب صغير من المذيبات. وتشتخدم شركات أخرى بروتين اللبن milk protein, lime, clay and earth مع الجير والصلصسال والأصباغ الأرضية الطبيعية latex, water-based paint ولضمان الأثر الماء .pigments الصحي للاهانات يجب أن تتخذ الاحتياطات الآتية عند تتفيذها:

• يجب أن ينم تهوية المبنى بصورة جيدة أثناء الدهانات، وبعدها لعدة أسابيع بعد التركيب لضمان التهوية الجيدة وتطاير كل المحتوى الكميائي الغير مرغوب. • من المستحب ترك النوافذ مفتوحة وتتغيل مروحة للتهوية، فإنبعاث الغازات المتطايرة يكون مرعين في ذروته بالأيام الأربعة الأولى ، من عملية الدهان والتشهيب.

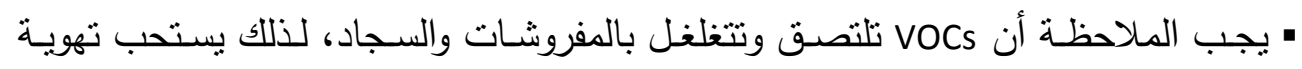
المكان تماما قبل فرشه. • لاحظ أن الألوان الفاتحة والباستيل محتواها من VOC أقل من المواد الداكنه والقوية.

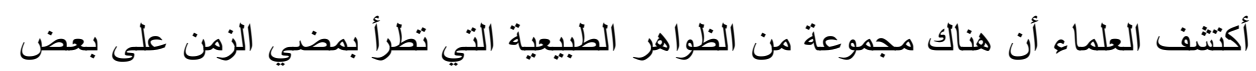
الأسطح المطلية بالدهانات مثل التآكل الاتسـاخ رائحة الرطوبـة, بل هناك مـا هو خطرا ويسبب بعض المشاكل الصحية لذا كان الاهتمام بما يسمى تطوير نظافة الأسطح, وليس المقصود هنا سهولة التظظيف وإنما المقصود هو تطوير الطلاء ليصبح ذاتي التظيف.(شكل V) 


$$
\text { المجلة العلمية بحوث في العلوم و الفنون النوعيه العدد الخامنبه عشر / المجلد الأول }
$$

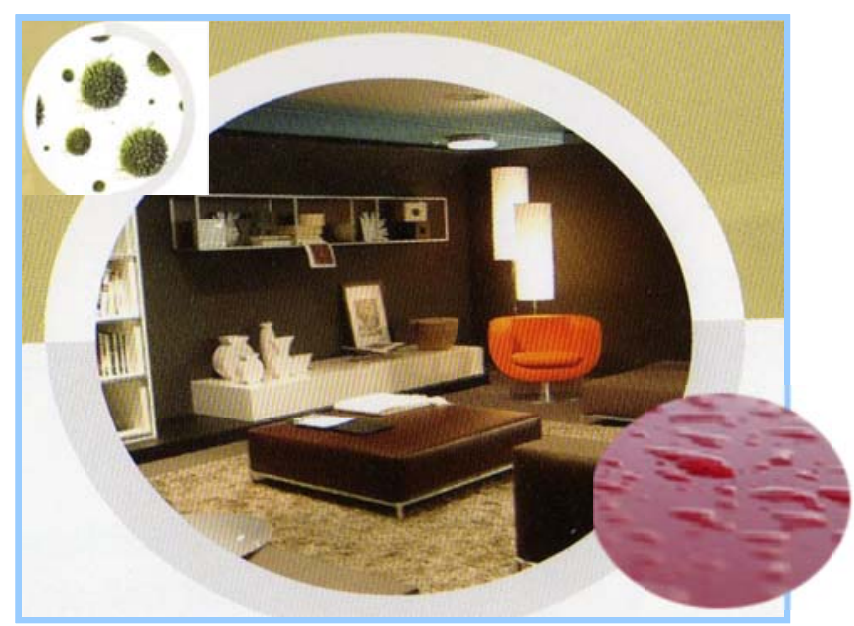

(شكل V ) يتم تحليل البكتيريا والميكروبات والأوساخ على شكل قطرات ذاتية التنظيف

تمكن العلماء من تحقيق هذه الخاصية للأسطح ( الأسطح الصحية) بواسطة طلاء النانو

الذي يحتوي على مبيد حيوي " Biocide " ذاتي التنظيف يعمل على تحليل البكتيريا والميكروبات Ag-Nan " والأوساخ والمكون الأساسي لهذا الطلاء صديق للبيئة وهو صغائر جزيئات الفضـة "TiO2-Nano particles " وثاني أكسيد التيتانيوم "particles

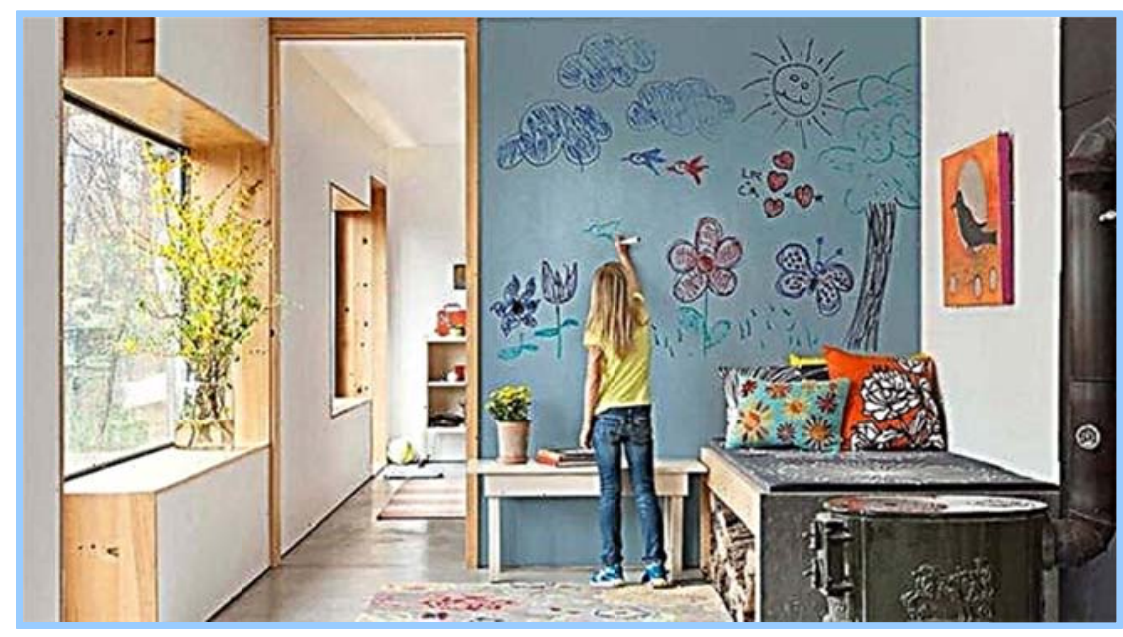

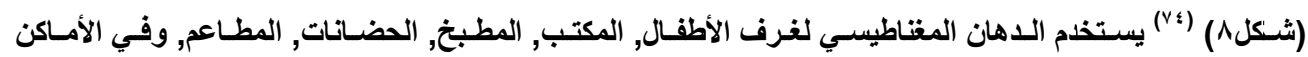

المناسبة لتطليق لوائح وغيرها ـ هو دهان أساس من اللاتكس ذي أساس مائي ، و هذا الطلاء صديق البيئة

www.ibtesama.com/vb/showthread-t $14253 . h$ html $\left({ }^{\text {Y⿷s }}\right)$ 


\section{ورق الحائط Wallpaper}

يعد ورق الحئط أحد مواد النهو والتشطيب للحوائط، من الناحية الصحية ويأني في المرحلة الثانية بعد الدهانات الصحية، وهناك أنواع تستخدم النسيج والخامات الطبيعية مما يجعلها صحية ولضمان أثر ورق الحائط الصحي يجب أن نتخذ الاحتياطات الآتية عند نركيبه:

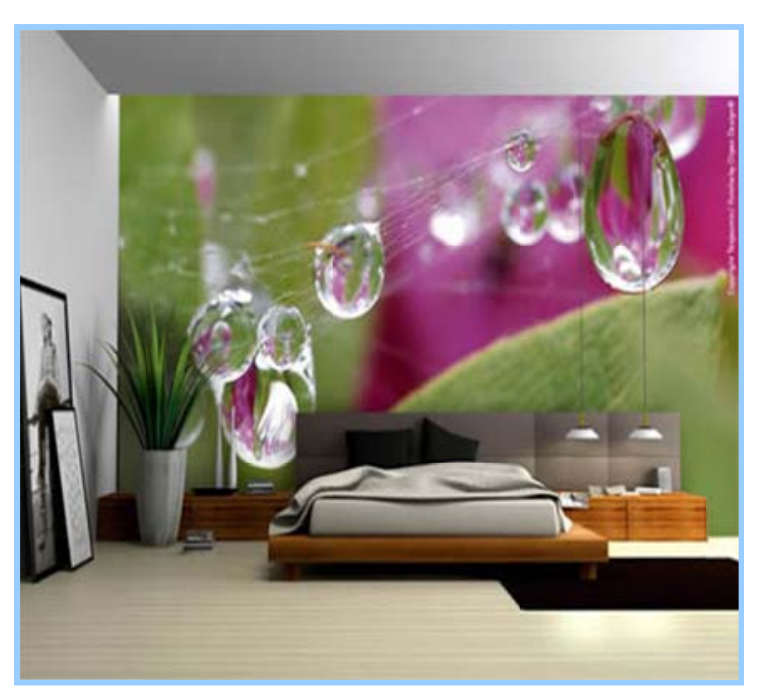

$$
\begin{aligned}
& \text { • أن تكــــن المــواد المســخدمة فـي } \\
& \text { لصقه خاليـة من السموم ومنخفضـة } \\
& \text { VOCs }
\end{aligned}
$$

• يجب النأكد انه لم يستخدم بـه مادة

$$
\text { PVC الفنيل }
$$

• ترك المبنى مفتوح لعدة أسـابيع بعد

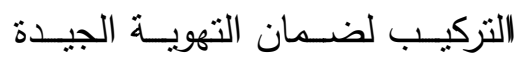

وتطـاير المحتـوى الكميـائي الغيـر

$$
\text { مرغوب فيه. }
$$

(شكل9) (10)

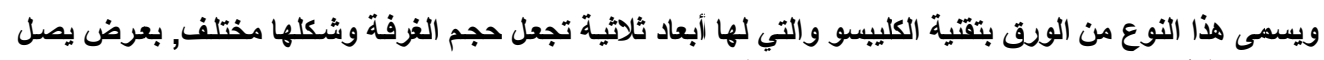

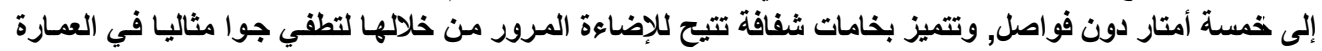

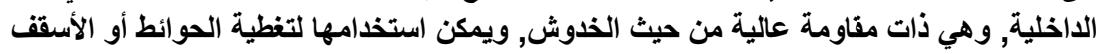

$$
\text { المو اد المستخدمة في الأرضيات }
$$

إن تجنب إستخدام السجاد من الحائط للحائط يعد بداية الحلول الصحية للمنزل، فالسجاد هو موطن عثة الغبار والبكتريا والتعفنات والأوساخ، كما أن العديد من أنواع السجاد المصنع مصدر قوي لغازات VOCs والكيماويات السامة. كما يجب تجنب استخدام الأرضيات الفنيل، فرغم شكلها المتميز ومميزاتها الوظيفية العديدة، الا أن الأرضيات الفنيل مصنوعة من أخطر أنواع اللدائن PVC وينبعث منها كم كبير من VOCs، وهي ضـارة جدا من الناحية الصحية لاسيما لمرضى 
الربو حيث تعد مثيرة للأزمات، وهناك العديد من بدائل الأرضيات الصحية مثل البامبو والفلين واللينوليم الطبيعي والخشب الطبيعي والتبليطات مثل الرخام والأحجار والسيراميك.

$$
\text { أرضيات البامبو }
$$

الأرضيات المصنوعة من اعواد نبات البامبو، والجزء الذي تصنع منه لا يسبب قطعه ضررا

مenewable resource مالنبات لذلك فإنه لا يؤثر بالسلب على البيئه لكون مصدره لاينضب

وهي لها شكل جميل ومميز ويشبه الخشب إلى حد بعيد (شكل^)، إلا أنها أقسى وأمتن وعملية أكثر من الخشب، ففي الوقت الذي تزداد صسلابته عن خشب الأوك northern red oak بمقدار

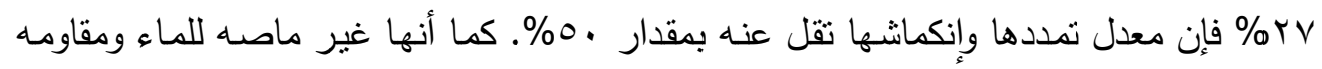
للفطريات والحشرات ولا تتبعث منها أي غازات منطايره أو جسيمات دقيقه.

أغلب أرضيات البامبو تستخدم urea formaldehyde كمادة غروية، وهي تعد صحية لكونها تطلق كم لايذكر من الفورمالدهيد في الهواء، كما بدأت الثركات نتتج أرضيات البامبو الخالي من الفورمالدهيد. ولضمان الأثر الصحي لها يجب أن تتخذ الاحتياطات الآتية عند تركيبه:

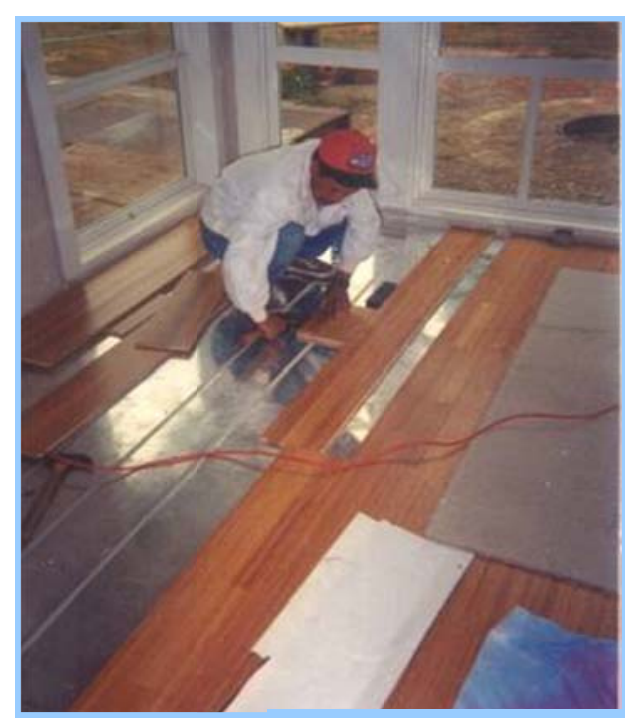

$$
\begin{aligned}
& \text { • أأن تكون المواد المستخدمة في تلميعة وورنشته } \\
& \text { VOCs من مواد خالية من السموم ومنخفضة }
\end{aligned}
$$

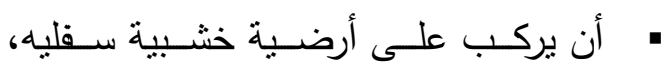

$$
\begin{aligned}
& \text { بالمسامير لا الغراء }
\end{aligned}
$$

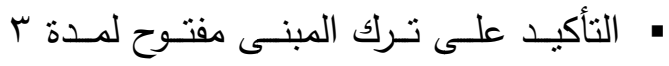

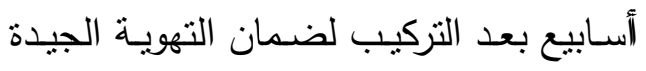

$$
\begin{aligned}
& \text { لأى مادة متطايرة محسسة أو ضارة صحيا } \\
& \text { (شكل - (1) (1) }
\end{aligned}
$$

أرضيات البامبو من أنواع الأرضيات الصحية

$\left({ }^{(* 7}\right)$ http://www.greenbuildersofmarin.com/GREEN\%20PROJECTS.htm 


$$
\text { المجلة العلمية بحوث في العلوم والفنون النوعيه العدد الخامس عشر / المجلد الأول }
$$

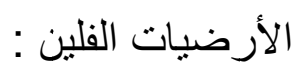

هى نوع من الأرضيات الطبيعية ذات مصدر لا ينضب Renewable resource أو يؤثز بالسلب على البيئه. وهي عالية الجودة ومقاومه للانزلاق وعازله للصوت، كما أنها جميلة ومتفردة (ثكل 9)، وهي مقاومه طبيعيه للعفن والرطوبه والعثه، كما أنها لا تتبعث منها أبي غازات منطايره أو جسيمات دقيقه. ولضمان أثرة الصحي يجب أن تتخذ الاحتباطات الآتية عند تركيبه: - أن تكون المواد المستخدمة في لصقه من مواد لاصقة خالية من السموم ومنخفضـة VOCs الحساسيته للماء لكونه نباتي التصنيع

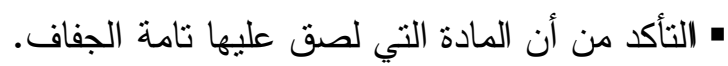
• التأكيد على ترك المبنى مفتوح لعدة أسابيع بعد التزكيب لضمان التهوية الجيدة التهان

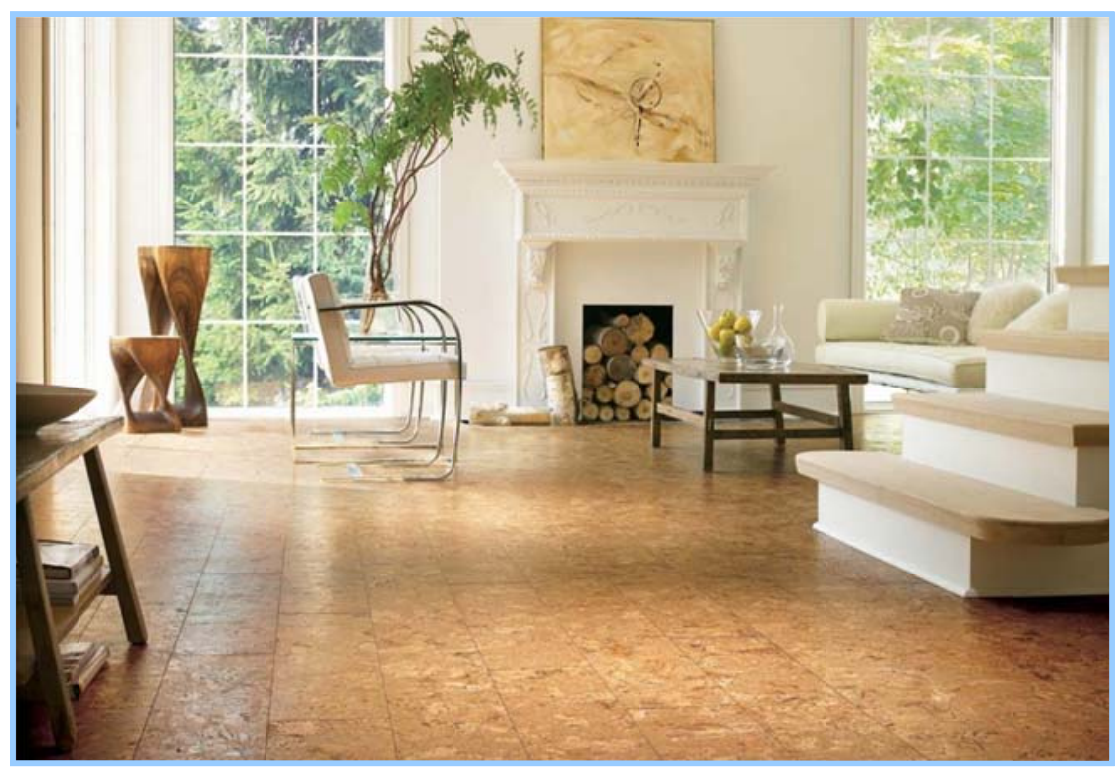

(شكلل 1) (1) أرضيات الفلين من أنواع الأرضيات الصحية وتعتبر أرضيات الفلين مادة آمنة بيئياً لإتتاج الطبقة العليا من بلوط الفلين. وهو مادة خام طبيعية فريدة من نوعهات الأريات 


$$
\text { المجلة العلمية بحوث في العلوم والفنون النوعيه العدد الخامس عثر / المجلد الأول }
$$

$$
\text { اللينوليم الطبيعي }
$$

linseed oil, pine resins, مصنوع من زبت بذر الكتان وصمغ الصنوبر مع نبات الجوته and jute، وهو يتميز بمقاومتة للخد الأحتكاك، ويعيش بحاله جيدة من • ؛:. . سنة. كما أنه منوفر بألوان عديدة وثابتة لكونها مستمرة بكامل سماكته (شكل ب ( ).

ومـن أهـ مميزاتـه أنـه مـادة صـحية كمـا أن زيـت بـذر الكتان المستخدم في صـناعته لـه خصائص مضادة للبكتريا. ولضمان أثرة الصحي يجب أن تتخذ الاحتياطات الآتية عند تركيبه:

• أن نكون المواد المستخدمة في لصقه من مواد لاصقة خالية من السموم ومنخفضة VOCS

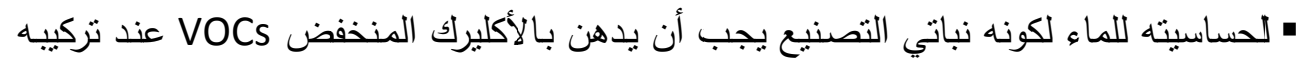

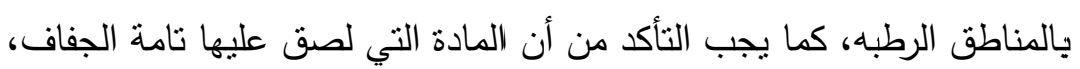

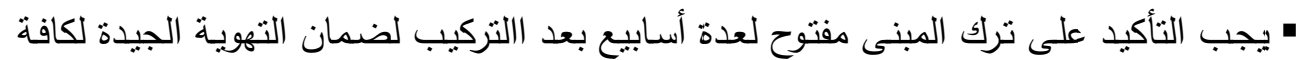

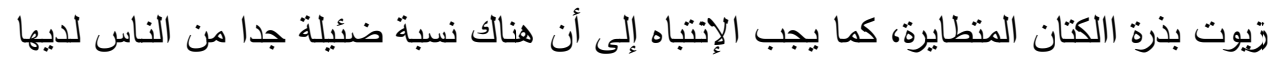
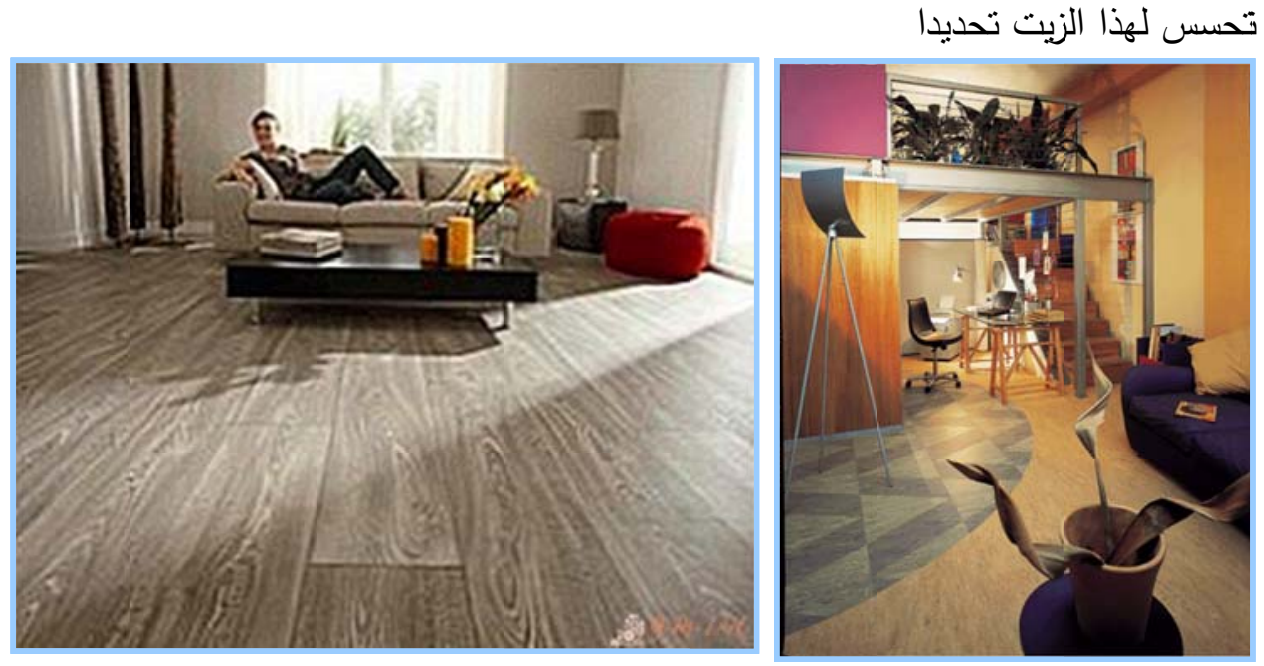

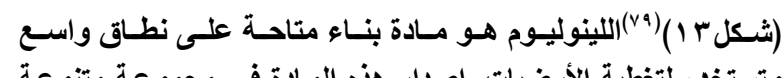

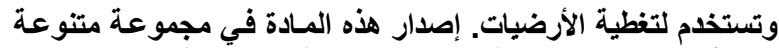
من الألوان. يتميز بسهولة التركيب والتكلفة المنخفضة.

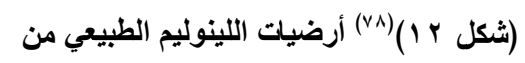

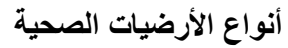

$\left({ }^{\vee \wedge}\right)$ http://www.greenbuildersofmarin.com/GREEN\%20PROJECTS.htm $\left(^{v a 9}\right)$ https://er.g-m-i.net/3611-which-linoleum-is-better-for-an-apartment.html 


\section{الأرضيات الخثبية الطبيعية}

المقصود الخشب الطبيعي الغير معالج ضد الرطوبة أو النمل الأبيض أو الحريق، فعمليات المعالجه هذه أغرقت البيئة بملايين الألواح الخشبية عالية السمية ومحسسة. كما أن أحد المواد التي يعالج بها الخشب، مادة Chromium Copper Arsenic (CCA), وهي يمكن أن يطلق عليها أنها سم زعاف. والخشب الطبيعي صحي وجميل الثكل ومتعدد الألوان وطرق التركيب ممـا يعطيه غنى بصري مميز • ولضمان أثزة الصحي يجب أن تتخذ الاحتياطات الآتية عند تركيبه: • أن تكون المواد المستخدمة في تلميعة وورنشته من مواد خالية من السموم ومنخفضة VOCs ـ أآن يركب على أرضية خشبية سفليه، بالمسامير لا الغراء

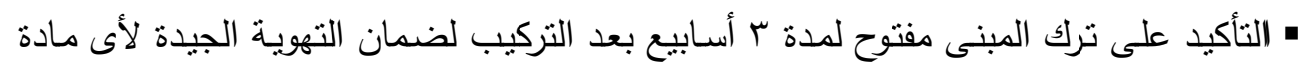

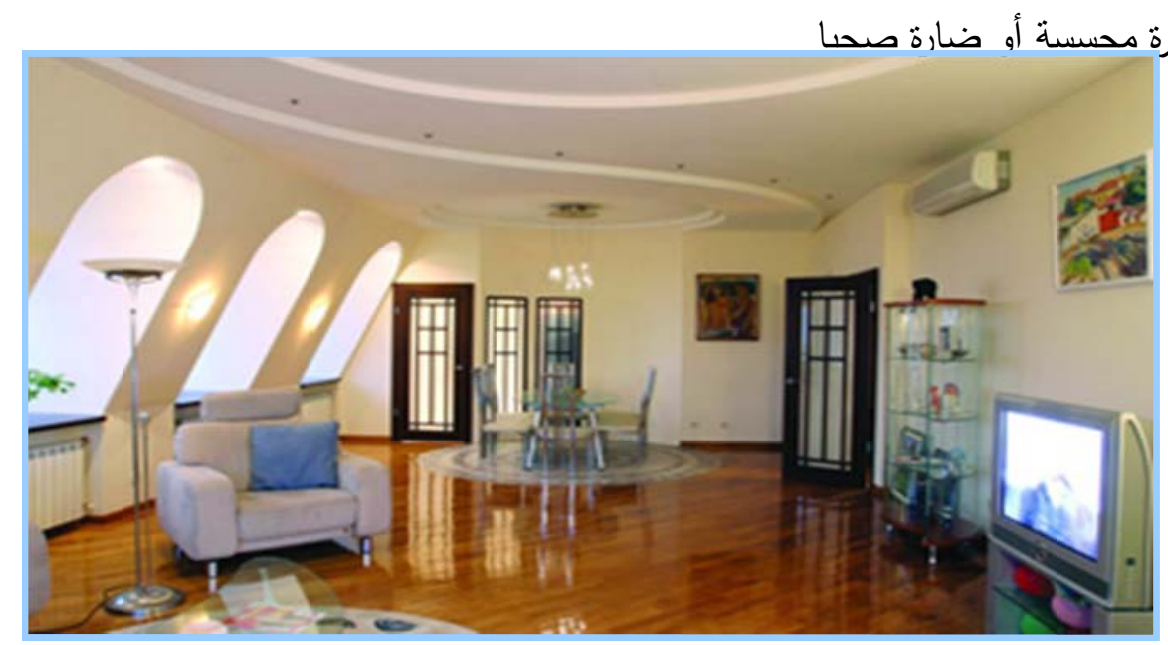

(شكل \& 1 ) تظهر فيها توظيف أسقف الجبسوم بورد في الأسقف والحوائط

$$
\text { التبليطات، الأحجار والرخام والسيراميك }
$$

هناك العديد من أنواع التبليطات، منها الطبيعي مثل الأحجار والرخام، ومنها المصنع من خامات طبيعية مثل السيراميك، وهذه التبليطات أغلبها صحي إذا توافر به الآتي:

• تكون المواد المستخدمة في تركيبه من مواد لاصقة خالية من السموم ومنخفضة VOCs

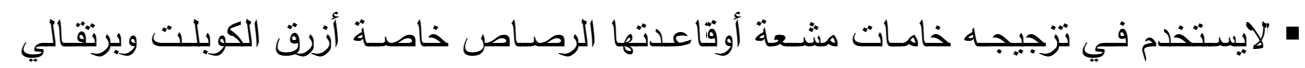


• لا يستخدم في معالجة وتلميع السطح النهائي مواد عالية VOCs أو عالية السمية

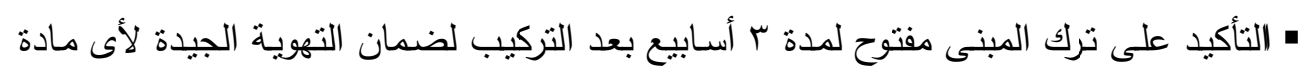
منطايرة محسسة أو ضارة صحيا

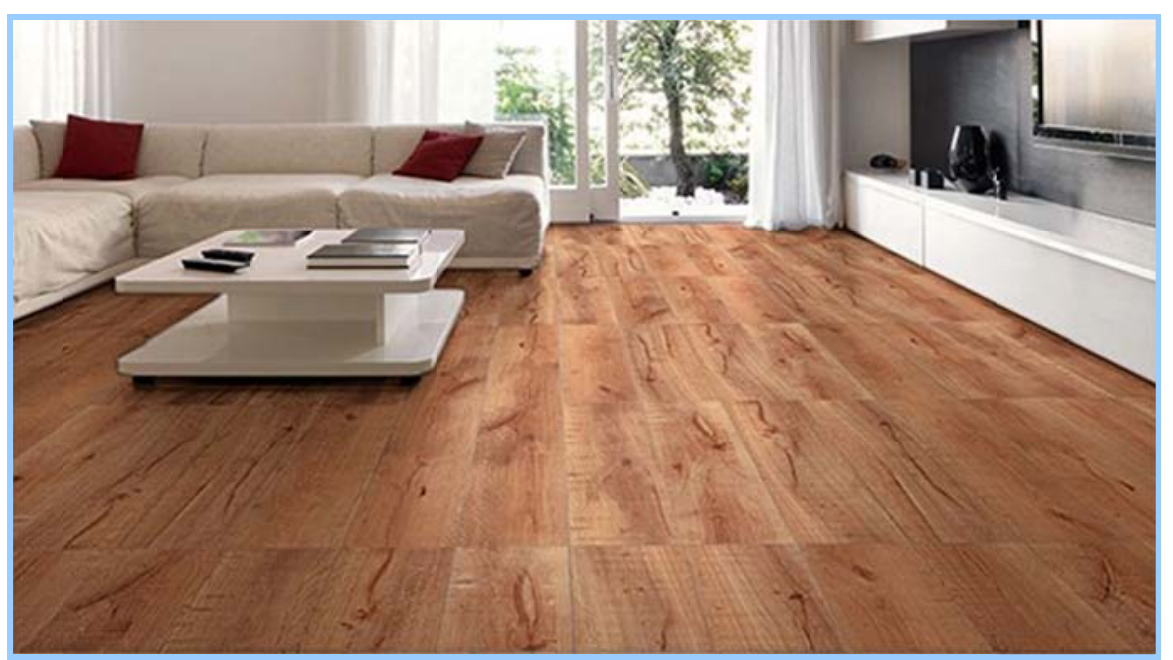

(تشكله (1.) يتميز هذا السير/ميك بالطابع الخثبي الذي يثبه الباركيه، و هو صحى وسهل التظظيف وأكثر نعومة السجاد المصنع من الألياف الطبيعية :

عند الضرورة يجب إستخدام السجاد المصنوع من الخامات الطبيعية مثل الصوف وألباف الأعشاب البحرية وليف جوز الهند wool, sea grass, coir, sisal مع ملاحظة عدم استخدام الصوف المعالج ضد الآفات لأن مادة المعالجة عالية السمية. وفي حالة الاضطرار لاستخدام سجاد صناعي فإن النوع الأقل ضررا هو . nylon ويجب ملاحظة الآتي لضمان الأثز الصحي للسجاد:

• يجب التأكد أن خلفية السجاد الطبيعي ليست مادة سامة أو محسسة مثل PVC • 'لا يكون وبر السجاد كثيف أو طويل، ومن المستحب أن تكون الخيوط ملتفة للداخل

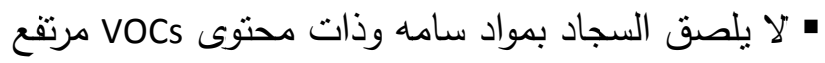

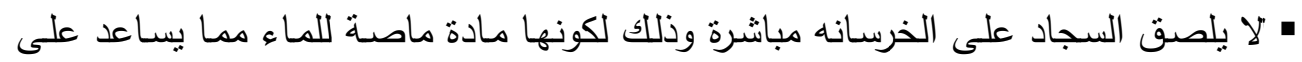
تكون العفن تحت السجاد إذا تعرض للبلل 


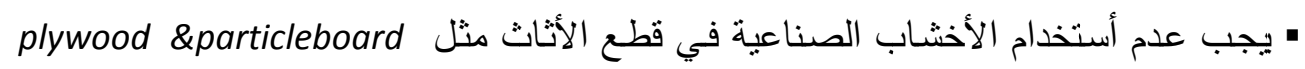

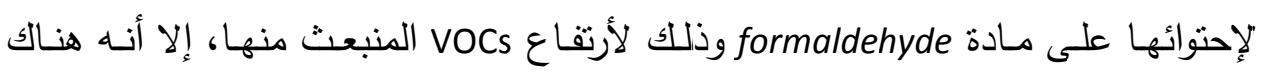

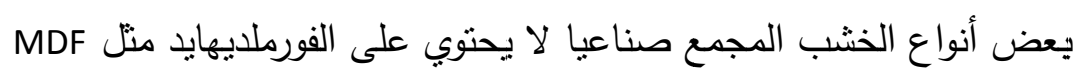
• يجب أن تكون قطع الأثاث من الخشب الطبيعي غير المعالج، ولكن عند الضـرورة

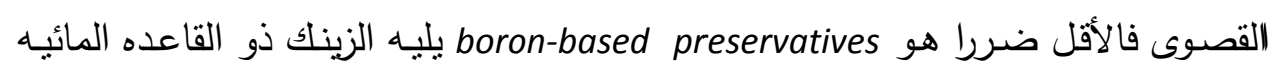

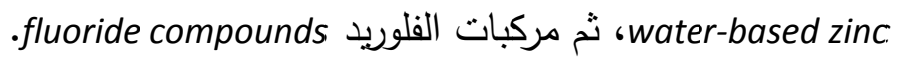
• يفضل أن يكون تصمم الأثاث بدون تجويفات وزخارف كثيرة تجمع الغبار ويصعب تنظيفها

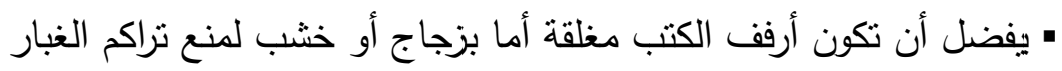

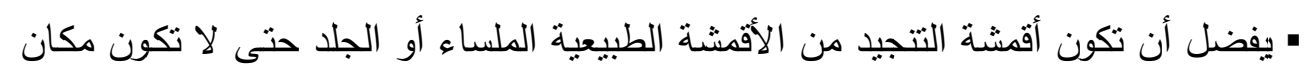

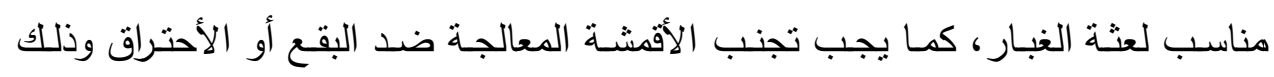
لأرتفاع VOCs المنبعث منها.

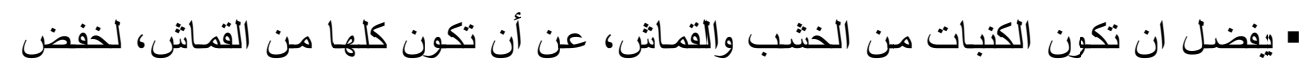
المحتوى الحيوي لعثة الغبار بها.

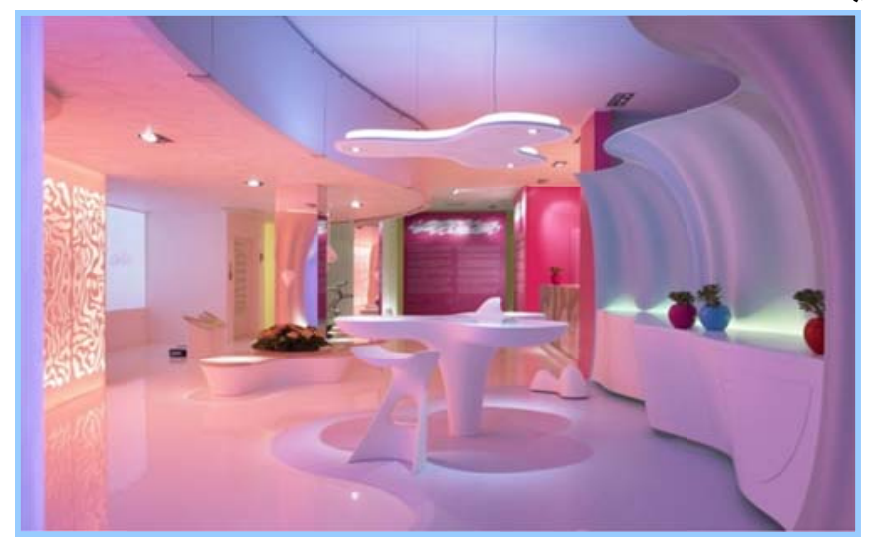

(شكل 14) (1) لقطة منظورية لغرفة معيشة، توظيف الخامات الذكية والحديثة التي توفرها التكنولوجيا الرقمية

http://interiii.com/2013/04/smart-ologic-corian-living-design-by-karim-rashid// $)^{\wedge}($ 


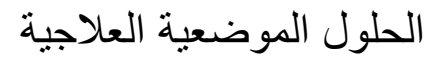

حلول ميكانيكية لخفض المحتوى الكميائي وتحسين جودة الهو اء يمكن إضافة العديد من المعدات القابلة للحركة للتحكم في درجة نقاء وجودة ورطوبة الهواء داخل المبنى، وذلك كالآتي:

Portable Air Purifiers with وضع وحدة تنقية هواء متنقلة HEPA (High Efficiency Particulate Absolute)

• أستخدام وحدة تحكم في الرطوية متنقلة Dehumidifiers

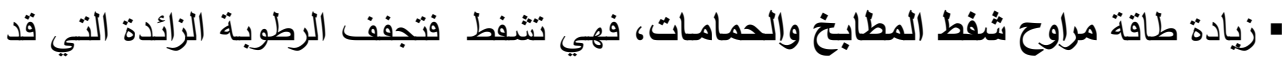
تؤدي لنمو الفطر والعفن، بالإظافة إلى غازات نواتج الإحتراق والروائح الغير مرغوب بهابها حلول ميكانيكية لخفض المحتوى الحيوي يلخص الجدول التالى (رقم ؟) بعض الحلول الميكانيكية التي تعالج مشكلة المحتوى الحيوي داخل البباني مثل وحدات تتقية الهواء والتحكم بالرطوبه ومكانس الجسيمات الدقيقه وأجهزة تنظيف البخار ـ وهي عدد من الأجهزه التي يسهل أستخدامها وتحريكها للتخلص من عثه الغبار والعفن والفطريات وحبوب اللقاح وشعر الحيوانات الليفه والقوارض. 


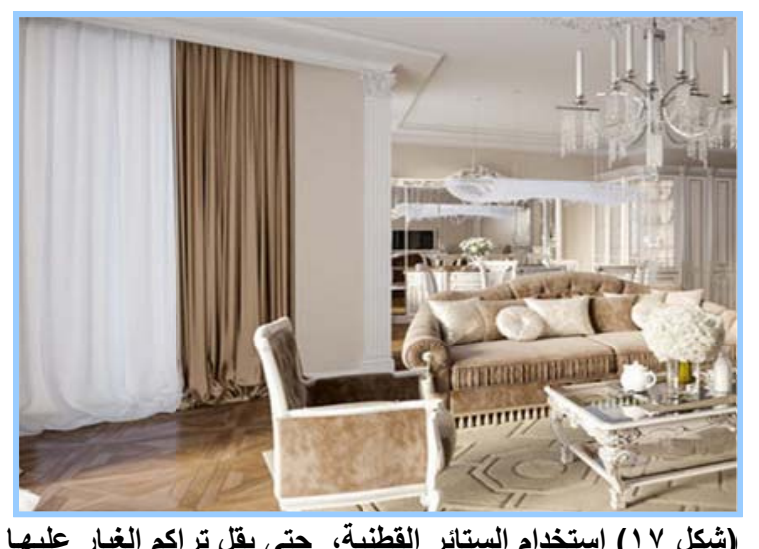

إستبدال الستائر المخملية كثيرة الطبات بأخرى بسيطه سهلة التنظيف، مثل الستائر القطنية البسيطة، والستائر الرأسية والأفقية، حتى يقل تراكم الغبار عليها ويسهل خلعها وغسـلها ممـا لا يترك مجـال لعثنة الغبـار (شكل V V I استخام الستائر القطنية، حتى يقل تراكم الغبار عليها

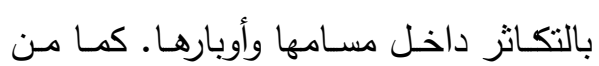

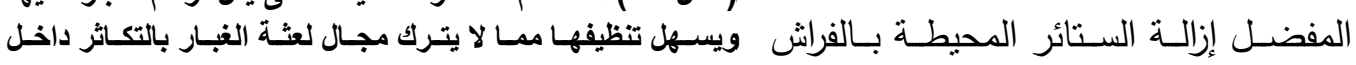
مسامها وأوبارها، يعطى شكل جمالى ( الثكل يتبع الوظيفة) حلول تصميمية، إضافة إكسسوارات جمالية وصحية (^^): 


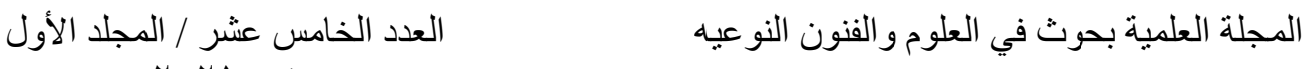

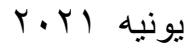
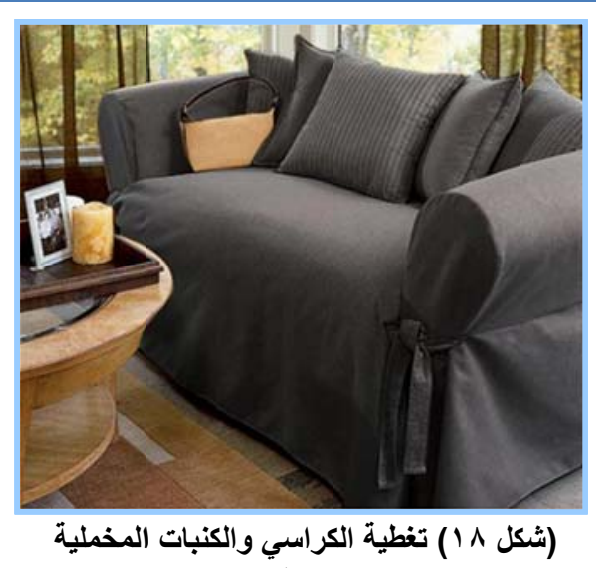
بكسوة قابلة للغسل الغراسي واكنبات

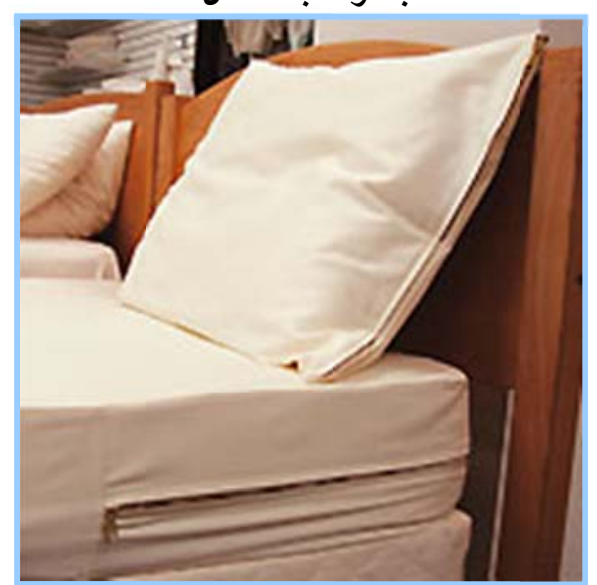

(شكل 9 (1) أغطيه واقية للمراتب والوسائد

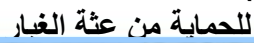

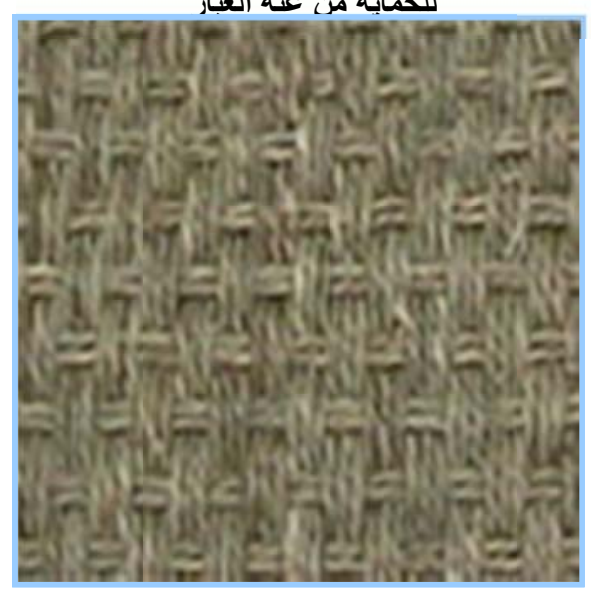

(شكل · r) (r) سجاد مصنع من الأعشاب البحرية
- تغطيـة الكراسـي والكنبـات المخمليـة بكسـوة قابلة للغنل

• تخطية وحدات الأثاث الوبربة أو ذات المسام

بكســات يسـهل غســلها وتتظيفهـا لتكـون

عـازل ببين المحتوى البيولـوجي لعثة الغبار

وبـين المسـتخدمين (شـكل م1)، وفي نفس

الوقـت تـوفر الاحتياجـات الجماليـة للحيـز

$$
\text { والتتوع اللوني لله }
$$

ه تغطية المراتب والوسائد بأغطية واقية قابلة

\section{لاغنسل}

- إســتخدام أغطيــه واقيــة للمراتـبـ والوســائد مخصصة للحماية من عثة الغبار (شكل 9 ()

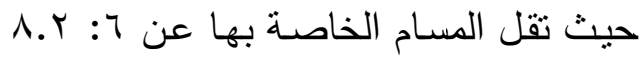
ميكرون، ثم أستخدام شرارشف قطنيـة فـقها يسـها غسـلها وغليها للتأكد من تطهيرهـا من عثة الفراش - تغطيـة الســاد الحـائطي المصـــع بســاد صغير من مصنع الأعشاب البحرية • إلذا كان الحيز مفروش بالسجاد بالفعل فيمكن الستخدام صغيرة Rug مصنعة من الأعشـاب البحرية (شكل · r)، حيث تمقتها عثة الغبار ولا تستطيع العيش بها، هذا النوع من السجاد متوفر في شكل سجاجيد صنغيرة وسجاجيد من الحائط للحائط أيضا.

$\left(^{\wedge}\right)$ http://www.greenbuildersofmarin.com/GREEN\%20PROJECTS.htm 
إستخدام النباتات للتسبق وفي ننفس الوقت تساعد على تقليل تلوث الهواء داخل المنازل،

نباتات الظل ليست مجرد أدوات جمال، فهي قد تجعل المنزل آمن صحيا، فلقد أثبتت الابحاث التي قامت بها وكالة NASA أن بعض أنواع النباتات تمنص أوراقها المواد السامه وتتقي المنزل،

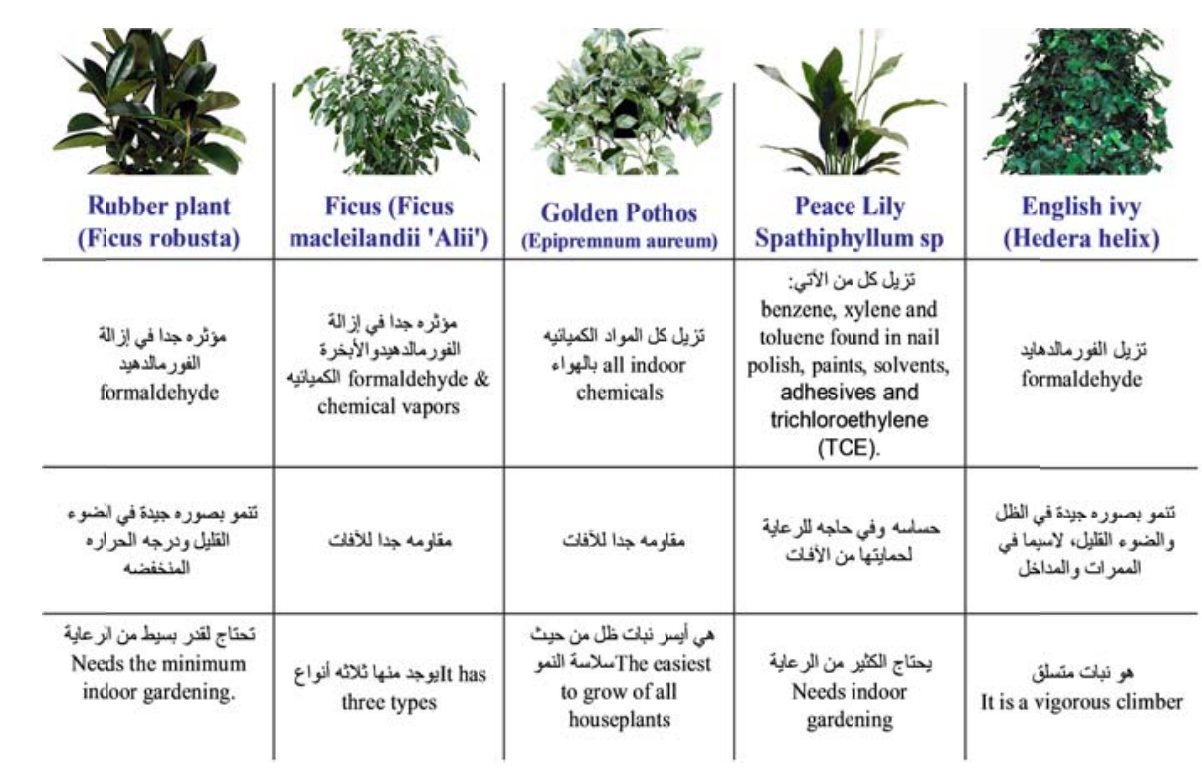

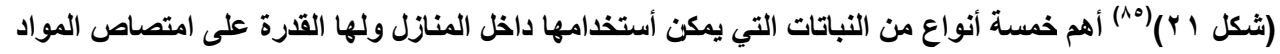

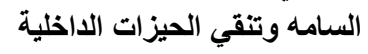

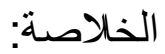

إن علم صناعة البناء ل اليجب أن يكون أبدا مستقل بذاته، فهو يجب أن يكون على رباط وثثق مع باقي العلوم التي يطوعها المصمم لخدمة احتياجات الإنسان وتوفير الراحة له. ولا شك أن العلـوم الصـحيه مـن أهم العلوم المرتبطـه بعمليـه تصـيم العمـارة الداخليـة للمبـاني السـكنية، فالإنسـان يقضـي تسعة أعشـار عمرة في داخلها والذي إن لم يتوفر بها الراحـة كان لذلك أثر عكسي على صحته الجسمانية والعقلية، ولا نيالغ ان قلنا أن المصمح ليس فقط قادر على أفساد عمل الطبيب، بل إنه قادر أيضا على تزويد المستشفيات بمرضى من نوع جديد!

$\left({ }^{85}\right)$ http://www.healthyhomeplans.com/articles/information25.php 
إنتهت هذه الدراسه إلى حصر نتاذرات أو متلازمة المبنى المريض في ثلاثة أعراض، هى :

$$
\text { - أ أن يكون الن بكون المحتوى الحيوي داخل المبنى مرتفع }
$$

ثم قامت الدراسـه بحصر الحلول الصحية التي تسـاهم بصورة وقائية وعلاجية لحل مشكلة مثيرات التحسس في المباني وتصنيفها في نوعين من الحلول:

- الأولى حلول جذرية ووقائية.... وهي التي يمكن اتخاذها قبل إنثاء المبنى أثناء مرحلة التصميم والتتفيذ لحماية المبنى من تلاك التتاذرات، وذللك كالآتي:

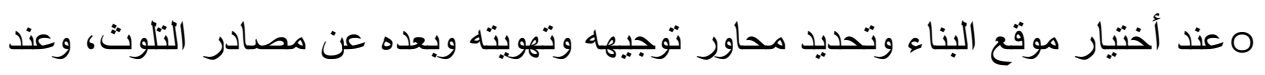
عمل المخططات المعمارية وشكل ومواقع الفتحات ومداخل التهويه الطبيعيه له، وكذلك وتلكاه

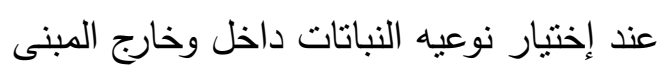

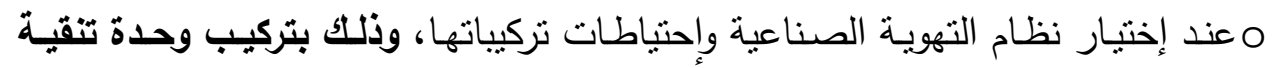
هواء على نظام التكييف المركزي وفلترات بنظام HEPA لينظف الهواء من كل العوالق مهما كانت دقتها، وكذلك أستخدام وحدة تحكم في الرطوبة Dehumidifier

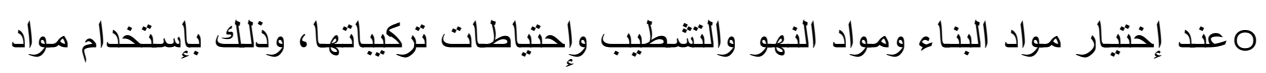

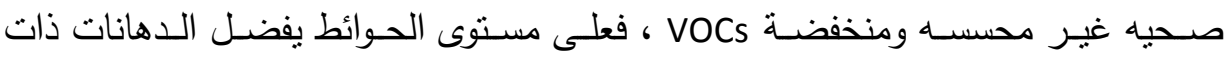

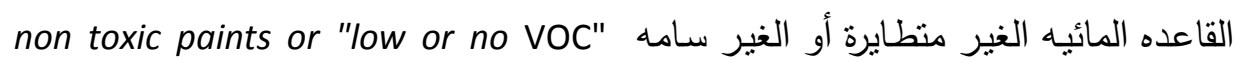
paint. والأخشاب الطبيعية غير المعالجة والأحجار والسيراميك أو السجاد ذو الألياف الطبيعية.

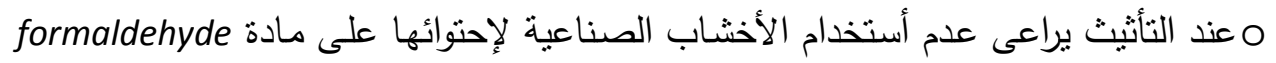
وإرتفاع VOCs المنبعث، كما يفضل الدكنبات المغلقه وألقمشه الطبيعية • الثانيـة حلـول موضعية وعلاجيـة... وهي التي يمكن إجراءها لعلاج مشكلات مبنى قائم

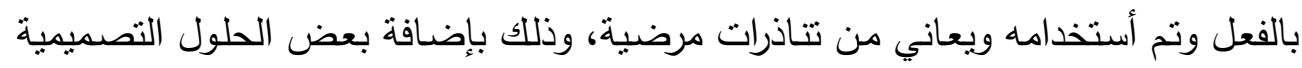
والميكانيكية النى تصل به وبسكانه إلى الراحه الصحية إن شاء الله 
0 حلول ميكانيكية لخفض المحتوى الكيمائي وتحسين جودة الهواء داخل المبنى، مثل وضـع وحدة تنقية هواء متنقلة و وحدة تحكم في الرطوبـة منتقلة وزيادة طاقة مراوح شفط المطابخ

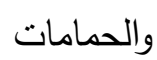

محلول ميكانيكية لخفض المحتوى الحيوي مثل آلات التنظيف بالبخار ومكانس الجسيمات الدقيقه بالإضافه لوحدات تتقية الهواء والتحكم في الرطوبه المتتقله محلول تصميمية، إضافة إكسوارات جمالية ولها أثز صحي في وقت واحد، مثل كسوات لترطهات الكراسـي و إستخدام أغطيـه واقيـة للمراتب والوسـائد مخصصـة للحمايـة مـن عثنة الغبـار ،

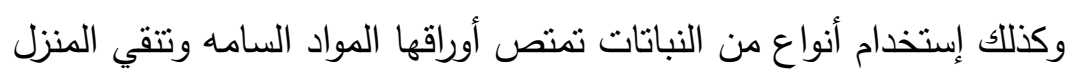

يجب على مصمم العمارة الداخلية أن يعيد تهيئة المفاهيم التقليدية للتصميم الداخلي ومقوماته وعناصره لكي تثتاسب وعصر التصميم الرقمي، فقد تغير مفهوم وظائف مقومات وعناصر التصميم الداخلي نتيجة للتطور التكنولوجي، حيث أصبح الهدف الأساسي لتصميم أي حيز داخلي هو تحقيق معيشة تفاعلية مع إحترام البيئة الداخلية والخارجية على حد سواء، بالإضافة إلى ضرورة نوافر إمكانية إحداث التغيير في شكل التصميم ووظيفته ليناسب الاحتياجات المستقبلية لمستخدمي المكان.

وأخيرا يجب القول أن صناعة الراحه والجمال هي حرفة المصمم الناجح، فهو الوحيد القادر على الدراسة والتحليل وإستيعاب ومراعاة العلوم المختلفه ثم الخروج بفكرة مبدعة لمبنى يحمل بين جدرانه كل سبل الراحة الجسمانية والراحة البصرية لمستخدميه. 


\section{المراجع العربية :}

• أسامة أحمد عبدة ومحمد سمير الصاوى، دراسة مبائية عن الإنبعاثات الصـادرة من مواد

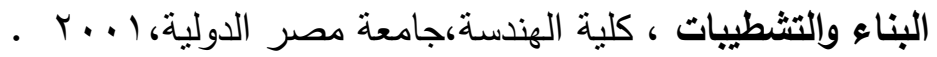

• عائشة حسن عبد العاطي محمد تطبيق مفهوم الإستدامة فى العمارة الداخلية للكهوف رسـالة دكتـوراة، قسـم الـديكور، شـعبة العهـارة الداخليـة، كليـة الفــون الجميلـة، جامعـة

$$
\text { الإسكندرية }
$$

• فرحات محروس، ملوثات البيئة الداخلية للمبانى وأعراض المبنـانى المريضـة، مؤسسـة

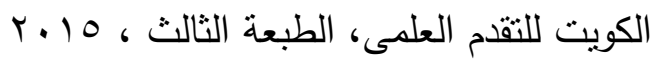

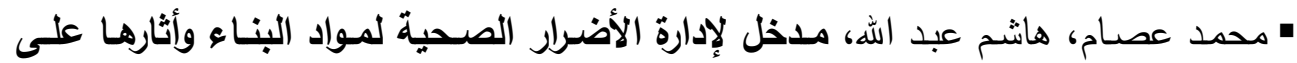
البيئة الاخليـة للمبـانى ، بحث علمى منشور، ضـمن فعاليـات المؤتتر العلىى، لكليـة

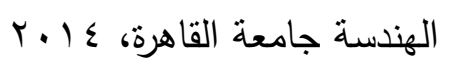

• مدحت لنشاذلى نظم الإنشاء البسيط ودورها في رفع كفاءة المستعمل في مجال تنمية المسكن ذاتيـا، بحث علمى منشور ضمن فعاليات المؤتمر العلمى الدولى للإسكان سيلسلت ونظم الإسكان لذوى الدخل المنخفض ، مركز بحوث الإسكان والبناء والتخطيط

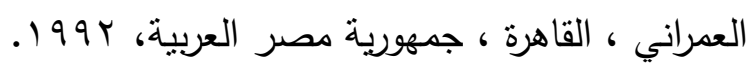
• يونجسن، روبرت، كيفية التعايش مع مرض الريو، كتاب مترجم، الناشر الأجنبي شيلدون برس، الناشر العربي دار الفاروق للنشر والتوزيع، مصر، هـ ـ. ب. 


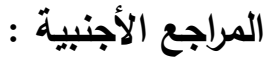

- Al Frayh AR, Shakoor Z, Gad El Rab MO, Hasnain SM. Parental smoking and the risk of childhood asthma, available at http://www.ncbi.nlm.nih.gov/pubmed/

- American Academy of Allergy, Asthma, and Immunology. [Web site], on the World Wide Web: http://www.aaaai.org/aadmc/default.htm

- D'Alessio, Vittoria; 2011- The Allergy-Free Home, A Practical Guide to Creating a Healthy

- Dr. Basel Khatib's Pediatric Web Site. http://khatib.com/index.htm, 2008

- D'Alessio, Vittoria;2001-The Allergy-Free Home,A Practical Guide to Creating a Healthy

- Dr. Basel Khatib's Pediatric Web Site. http://khatib.com/index.htm, 2008

- World Health Organization, 2008, Regional office for Europe.

- http://www.healthybuilding.net/pdf/Healthy Building MaterialResources

- Tohn, Ellen, 2006, Building Guidance for Healthy Homes, ARC, Asthma Regional Council of New England, available at, www. asthmaregiona Icouncil.org

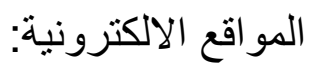

- http://www.algedra.qa/

- www.ibtesama.com/vb/showthread-t 14253.html

- http://www.love-m.com/vb/t382335.html

- http://www.greenbuildersofmarin.com/GREEN\%20PROJECTS.htm

- https://ar.decoratex.biz/pol/derevyannyj/probkovyj/

- http://www.greenbuildersofmarin.com/GREEN\%20PROJECTS.htm

- https://er.g-m-i.net/3611-which-linoleum-is-better-for-an-apartment.html

- https://www.supermama.me/posts/

- http://interiii.com/2013/04/smart-ologic-corian-living-design-by-karim-rashid/

- http://www.healthyhomeplans.com

- http://www.healthyhomeplans.com/articles/information25.php 